\title{
HACIA UN NUEVO Y DIFERENTE "FLANCO SUR" EN EL GRAN MAGREB-SAHEL
}

\author{
Raquel Barras ${ }^{1}$ y David García ${ }^{2}$ \\ UNISCI/Universidad Complutense de Madrid
}

\begin{abstract}
Resumen:
La unión de espacios subgobernados, la corrupción, el crimen organizado y terrorismo es la amenaza a la que se enfrenta la UE y sus estados miembros en el Gran Magreb, el cual está recreando un nuevo y diferente Flanco Sur al que existía durante la Guerra Fría. El aumento de la actividad extremista en la región del Sahel-Sáhara a partir de 2005 ha ido en paralelo con el crecimiento de las redes de crimen organizado transnacional a través del área. Aunque hay un intenso debate sobre su relación, intensidad e impacto, es una dinámica innegable en el área. La UE no tiene realmente una política unificada Magreb-Sahel y en términos de crimen organizado y terrorismo, el Sahel no se puede separar del Magreb. Hay una comprensión limitada y parcial del problema tanto en términos de amenazas como en soluciones viables, ampliado irremediablemente por la acción de Boko Haram y desbordando la visión, proyección y estrategia de la UE. A pesar del "Sahel Regional Action Plan 2015-2020", las medidas tomadas son reducidas, muy recientes y probablemente insuficientes y tardías desde el punto de vista de la dinámica y sinergia entre terrorismo-crimen organizado en un contexto de corrupción. La UE sigue manteniendo un enfoque seguridad-desarrollo, básicamente en una concepción de seguridad humana, a pesar de que este enfoque es altamente discutible para enfrentarse a este tipo de amenazas.
\end{abstract}

Palabras clave: Magreb-Sahel, terrorismo, crimen organizado, política de la UE, Flanco sur, conflictos híbridos, espacios subgobernados.

Title in English: "Towards a new and different "South Flank" in the Great Maghreb-Sahel"

\section{Abstract:}

The network created by undergoverned spaces, corruption, organized crime and terrorism is the threat that the EU and its member states faced in the Great Maghreb, which is recreating a new Southern Flank, different from that which existed during the Cold War. The increase in extremist activity in the Sahel-Sahara since 2005 has gone hand in hand with the growth of transnational organized crime networks through the area. Although there is much debate about their relationship, intensity and impact, it is an undeniable dynamics in the area. The EU does not really have a unified policy for the Maghreb-Sahel, and in terms of organized crime and terrorism, the Sahel cannot be separated from the Maghreb. There is a limited and partial understanding of the problem both in terms of threats and viable solutions, a problem which has expanded by the action of Boko Haram, overwhelming the vision, planning and strategy of the EU. Despite the Sahel Regional Action Plan 2015-2020, the measures taken are limited, very recent and probably insufficient from the point of view of the dynamics and synergies between terrorism-organized crime in a context of corruption. The EU continues to maintain a security-development approach essentially based on a concept of human security, although this approach is highly questionable to face such threats.

Keywords: Maghreb-Sahel, terrorism, organized crime, EU policies, Southern Flank, hybrid conflicts, ungoverned spaces.

Copyright (C) UNISCI, 2015.

Las opiniones expresadas en estos artículos son propias de sus autores, y no reflejan necesariamente la opinión de UNISCI. The views expressed in these articles are those of the authors, and do not necessarily reflect the views of UNISCI.

\footnotetext{
${ }^{1}$ Raquel Barras Tejudo es investigadora junior de UNISCI y miembro del Foro Hispano-Argelino.

E-mail: raqueltejudo@yahoo.es.

${ }^{2}$ El Dr. David García Cantalapiedra es profesor de Relaciones Internacionales en la Facultad de Ciencias Políticas de la Universidad Complutense de Madrid, investigador senior de UNISCI y miembro del Foro Hispano-Argelino.

Dirección: Departamento de Estudios Internacionales, Facultad de Ciencias Políticas y Sociología, UCM, Campus de Somosaguas, 28223 Madrid, España.

E-mail: djgarcia@pdi.ucm.es.
} 


\section{Introducción}

\subsection{Conflictos híbridos y espacios subgobernados}

Existe toda una amplia bibliografía y extenso debate sobre la naturaleza de los conflictos actuales y el futuro de la guerra en general establecida por varios vectores: el fin de la Guerra Fría, el 11-S, la RMA, el concepto de Nuevas Guerras (New Wars) ${ }^{3}$, el ascenso y caída de COIN (Counter-insurgency) ${ }^{4}$, junto con el debate sobre un sistema post Westfaliano, con las premisas de una nueva estructura del sistema internacional con mega-urbes y espacios desgobernados. No es el objeto de este articulo debatir sobre la naturaleza y definición de los conflictos o guerras hibridas ${ }^{5}$, aspecto el cual es bastante discutido en el ámbito doctrinal y militar, sino analizar las dinámicas que se producen en espacios de gobierno híbridos desde el punto de vista de su control, gestión y jurisdicción, como marco general donde se desarrollan las llamadas amenazas híbridas. Así, nos interesa más el espacio donde se produce el conflicto o la guerra, ya que en gran medida sus características van a contribuir también a la naturaleza de ese conflicto y en qué punto del espectro se encuentra. En este sentido, y sobre gran parte de la literatura de los conflictos híbridos y COIN norteamericana se refieren a los llamados espacios desgobernados (ungoverned spaces), concepto que aparece como consecuencia del desarrollo del debate sobre los estados fallidos (failed states) ${ }^{6}$ desde principio de los años 90 .

El Departamento de Defensa de EEUU lo definía en 2008 como "ungoverned area": "A place where the state or the central government is unable or unwilling to extend control, effectively govern, or influence the local population, and where a provincial, local, tribal, or autonomous government does not fully or effectively govern, due to inadequate governance capacity, insufficient political will, gaps in legitimacy, the presence of conflict, or restrictive norms of behavior... the term 'ungoverned areas' encompasses under-governed,

\footnotetext{
${ }^{3}$ Kaldor, Mary (2013): In Defence of New Wars. Stability, 2(1): 4, pp.1-16; Kaldor Mary (2007): New \& Old Wars: Organized Violence in a Globalized Era. Stanford: Stanford University Press.

${ }^{4}$ Kaplan, Fred "The End of the Age of Petraeus. The Rise and Fall of Counterinsurgency", Foreign Affairs, essay, January-February 2013, pág.75-90.

${ }^{5}$ Mattis James N. y Hoffman Frank: Future Warfare: The Rise of Hybrid Wars, US Naval Institute, Proceedings, Nov. 2005, en http://milnewstbay.pbworks.com/f/MattisFourBlockWarUSNINov2005.pdf; Frank G. Hoffman, Hybrid Warfare and Challenges, Joint Forces Quarterly, nº 52, 2009, en

http://smallwarsjournal.com/documents/jfqhoffman.pdf; Conflicts in the 21st Century: The Rise of Hybrid Wars, Potomac Institute for Policy Studies, Arlington, Virginia, 2007, en

http://www.potomacinstitute.org/images/stories/publications/potomac hybridwar_0108.pdf; Hoffman, Frank G. : Hybrid vs. Compound War: The Janus Choice of Modern War: Defining Today's Multifaceted Conflict, Armed Forces Journal, October 2009, en http://www.armedforcesjournal.com/hybrid-vs-compound-war/; Fleming Bryan P. : The Hybrid Threat Concept: Contemporary War, Military Planning and the Advent of Unrestricted Operational Art, School of Advanced Military Studies, United States Army Command and General Staff College, Fort Leavenworth, Kansas, 2011, en https://www.hsdl.org/?view\&did=700828; Huber Thomas M.: Compound Warfare: That Fatal Knot, US Army Command and General Staff College Press, Fort Leavenworth, Kansas, 2002, en http://www.au.af.mil/au/awc/awcgate/army/compound_warfare cgsc.pdf; Calvo Albero José Luis: La Evolución de las Insurgencias y el Concepto de Guerra Híbrida, Revista Ejército, $\mathrm{n}^{\circ}$ 822, Ministerio de Defensa, Madrid, 2009; Liang Qiao and Xiangsui Wang : Unrestricted Warfare, PLA Literature and Arts Publishing House, Beijing, 1999; Bond, Margaret S. : Hybrid War: A New Paradigm for Stability Operations in Failing States, U.S. Army War College, Pensilvania, marzo 2007, en

http://www.researchgate.net/publication/235029315 Hybrid_War_A_New_Paradigm_for_Stability_Operations in Failing_States; Freier Nathan: "The Defense Identity Crisis: It's a Hybrid World", Parameters, vol. $39, \mathrm{n}^{\circ} . \overline{3}$, otoño, 2009; McCuen John J.: Hybrid Wars, Military Review, marzo-abril, 2008; McWilliams Sean: Hybrid War Beyond Lebanon: Lessons from the South African Campaign 1976 to 1989, School of Advanced Military Studies, United States Army Command and General Staff College, Fort Leavenworth, Kansas, 2009.

6 "A failed state as a condition of state collapse, whereby the state can no longer perform its basic security and development functions and has no effective control over its territory and borders" Di John, Jonathan. Conceptualizing the Causes and Consequences of Failed States: A Critical Review of the Literature. Crisis States Working Paper Series No. 2, Working Paper No. 25. London: Crisis States Research Centre. 2008, pp. 9-10.
} 
misgoverned, contested, and exploitable areas as well as ungoverned areas. ${ }^{7 "}$. En 2012, el US Defense Strategic Guidance también hablaba de los espacios desgobernados: "For the foreseeable future, the United States will continue to take an active approach to countering these threats by monitoring the activities of non-state threats worldwide, working with allies and partners to establish control over ungoverned territories, and directly striking the most dangerous groups and individuals when necessary". ${ }^{8}$ Finalmente, la estrategia militar de 2015 define claramente la relación entre estos espacios y el nexo grupos terroristas (organizaciones extremistas violentas y crimen organizado: "Concurrent with state challenges, violent extremist organizations (VEOs) — led by al Qaida and the self-proclaimed Islamic State of Iraq and the Levant (ISIL) - are working to undermine transregional security, especially in the Middle East and North Africa. Such groups are dedicated to radicalizing populations, spreading violence, and leveraging terror to impose their visions of societal organization. They are strongest where governments are weakest, exploiting people trapped in fragile or failed states. In many locations, VEOs coexist with transnational criminal organizations, where they conduct illicit trade and spread corruption, further undermining security and stability"'.

Sin embargo es interesante como la mayoría de la literatura prestará atención a ese término y no al siguiente que aparece en el párrafo de la estrategia norteamericana de 2004, undergoverned spaces, o espacios sub-gobernados, aunque posteriormente aparecerán estudios que comiencen a hablar de sistemas políticos híbridos ${ }^{10}$. Realmente la mayoría de los espacios identificados tiene diferentes grados de gobierno, y solo muy pocos caerían en la categoría de desgobernados totalmente (quizá Somalia en algunos momentos). Es importante la definición debido a que la literatura de los conflictos híbridos se mueve no solo en espacios desgobernados sino en espacios tanto densamente poblados ${ }^{11}$ como en grandes territorios vacíos. Estas características hacen más fácil la aparición de "amenazas híbridas". Las amenazas "clásicas" serían el crimen organizado, la insurgencia y el terrorismo, pero la dinámica de estas amenazas clásicas en este tipo de espacios ha dado lugar a las llamadas amenazas híbridas como la narco-insurgencia o el crimen-terrorismo transnacional.

Así, estas amenazas híbridas trabajan en espacios que según la literatura serían subgobernados, no totalmente desgobernados, como ocurre entre el Sahel y el Magreb. Hay también grupos o actores no estatales que realmente lo hacen. Sin embargo, deberíamos de pensar que estos son espacios de gobierno híbrido, ya que conviven diferentes tipos de gobierno, de forma o no simbiótica ${ }^{12}$. Realmente no existe solo una definición de espacios gobernados o no gobernados, sino un continuum de diferentes grados y características en

\footnotetext{
${ }^{7}$ Lamb, Robert D. (2008): "Ungoverned Areas and Threats from Safe Havens". Final Report of the Ungoverned Areas Project. Prepared for the Office of the Undersecretary of Defense for Policy by the Office of the Deputy Assistant Secretary of Defense for Policy Planning, p. 18.

${ }^{8}$ United States Department of Defense (2012): "Sustaining U.S. Global Leadership: Priorities for $21^{\text {st }}$ Century Defense". Defense Strategic Guidance .Washington, United States Department of Defense, p. 1.

9 CJCS: "The National Military Strategy of the United States of America". The United States Military's Contribution to National Security, Junio 2015.

${ }^{10}$ Véase por ejemplo Mallett, Richard: 'Beyond Failed States and Ungoverned Spaces: Hybrid Political Orders in the Post-Conflict Landscape'. eSharp, Issue 15: Uniting Nations: Risks and Opportunities. 2010, pp. 65 - 91 , en http://www.gla.ac.uk/media/media 153492 en.pdf

11 Stephen Graham: "RoboWar TM Dreams: Global South Urbanisation and the US Military's 'Revolution in Military Affairs". Working Paper No. 20- Cities and Fragile States - LSE Crisis States Working Papers Series No.2, Noviembre 2007; Kilcullen David (2013): Out of the Mountains: The Coming Age of the Urban Guerrilla, New York, Oxford University Press.

${ }^{12}$ Véase Bergeron, J.: "Transnational Organised Crime and International Security". The RUSI Journal, $158: 2$. 2013, pp. 6-9; Madsen, F.: "Corruption: A Global Common Evil", The RUSI Journal, 158:2. 2013, pp. 26-38; Cockayne, J.: "Chasing Shadows", The RUSI Journal, 158:2, 2013, pp.10-24.
} 
relación al gobierno de esas áreas ${ }^{13}$, que debe ser correctamente analizado para producir políticas y estrategias realmente viables.

\subsection{Terrorismo-Crimen Organizado Transnacional: una Joint Venture de gran éxito ${ }^{14}$}

Expertos y autores ya consideraban a finales del siglo XX y principios del XXI que la diferencia entre crimen organizado y terrorismo que se mantenía hasta finales de los años 90, sin embargo se advertía ya borrosa y en algunos casos se había producido una simbiosis entre ambos que antes no existía. El final de la Guerra Fría y el tráfico internacional de drogas habían abierto nuevas oportunidades para los patrocinadores del terrorismo y para los grupos terroristas. A la vez, la delincuencia organizada se estaba volviendo cada vez más politizada, con intereses no solo en las ganancias sino en el poder político ${ }^{15}$. El 9 de diciembre 1994, la Asamblea General de las Naciones Unidas aprobó una Declaración sobre medidas para eliminar el terrorismo internacional en el que se expresa, entre otras cosas, su preocupación "por las crecientes y peligrosos vínculos entre grupos terroristas y traficantes de drogas y sus bandas paramilitares, que tienen recurrido a todo tipo de violencia, poniendo así en peligro el orden constitucional de los Estados y de violar los derechos humanos básicos". En la línea de la política de Guerra Global al Terror ${ }^{16}$ tras los atentados del 11-S, la Resolución del Consejo de Seguridad 1373 (2001) establece que "toma nota con preocupación la estrecha conexión entre el terrorismo internacional y la delincuencia transnacional organizado, las drogas ilícitas, el blanqueo de dinero, el tráfico de armas, y la circulación ilícita de materiales nucleares, químicos, biológicos y otros materiales potencialmente letales". ${ }^{17} \mathrm{Sin}$ embargo, existían aún diferencias entre ambas organizaciones que llevaban a mantener cierta distancia con esta concepción. Por ejemplo, en cuanto a las evidencias empíricas encontradas. En el año 2004 Yvon Dandurand y Vivienne Chin, publicaron un informe sobre la relación entre estas organizaciones donde afirmaban que "The available responses from Member States indicated that terrorist groups are frequently involved in other crimes, particularly illegal drug trafficking, smuggling of migrants, falsification of travel and identity documents, trafficking in firearms and exploitation of illegal markets, inter alia, to support their activities. However, the responses did not provide strong evidence of organizational links between terrorist groups

\footnotetext{
${ }^{13}$ Existe un debate sobre las posiciones en cuanto al sistema internacional de tipo westfaliano y de características weberianas. Véase, entre otras, por ejemplo Lake, David: "Escape from the State of Nature: Authority and Hierarchy in World Politics," International Security, 32/1 (Summer 2007): 47-79; Lake David A.:"Rightful Rules: Authority, Order, and the Foundations of Global Governance" International Studies Quarterly (2010) 54, pp. 587-613.

${ }^{14}$ Ya a finales de los años 80 se establecía la primera relación entre el terrorismo y el tráfico de drogas. Véase Wardlaw Grant: "Linkages between the Illegal Drugs Traffic and Terrorism," Paper prepared for the Conference on International Drugs: Threat and Response, Defense Intelligence College, Washington, US, June 2-3, 1987. Uno de los primeros que establecieron de forma actualizada esta relación fue Makarenko Tamara: "The CrimeTerror Continuum: Tracing the Interplay between Transnational Organised Crime and Terrorism". Global Crime. Vol. 6, No. 1, February 2004, pp. 129-145; también Sanderson Thomas M.: "Transnational Terror and Organized Crime: Blurring the Lines". SAIS Review, Vol XXIV, n.1. Winter-Spring 2004; con un enfoque en el Norte de África-Sahel, véase Hübschle Annett: "From Theory to Practice: Exploring the Organised Crime-Terror Nexus in Sub-Saharan Africa". Perspectives on Terrorism. Septiembre 2011, pp. 81-93.

${ }^{15}$ Laqueur Walter (1999): The New Terrorism, Oxford: Oxford University Press, p. 211.

${ }^{16}$ Sobre el concepto de GWOT y sus orígenes en la Doctrina Reagan, que unía terrorismo, islamismo radical, crimen organizado, armas de destrucción masiva y Rogue States, para tratarlo como un conflicto de baja intensidad (Low Intensity Conflict) véase Garcia Cantalapiedra, David: "Irak, la política exterior de EEUU y las elecciones presidenciales de noviembre". UNISCI Discussion Papers, Octubre 2004. Para una explicación ampliada sobre la GWOT véase García Cantalapiedra, David (2003): "Peace through Primacy". La Administración Bush, la politica exterior de EEUU y las bases de una Primacía Imperial. UNISCI Paper $n^{\circ} 30$, Madrid, UNISCI.

${ }^{17}$ Resolución 1373 (2001) aprobada por el Consejo de Seguridad en su 4385ª sesión, 28 de septiembre de 2001. S/RES/1373 (2001), en http://www.un.org/es/comun/docs/?symbol=S/RES/1373(2001)
} 
and organized crime groups" ${ }^{18}$ Aun así los autores advertían que los grupos terroristas se acabarían transformando en grupos predominantemente criminales ${ }^{19}$. El aumento de la actividad extremista en la región del Sahel-Sáhara a partir de 2005 ha ido en paralelo con el crecimiento de las redes de tráfico de drogas a través del área. Aunque hay un intenso debate sobre su relación, intensidad e impacto ${ }^{20}$, es una dinámica innegable en el área que influye de manera clave en el Sahel y Norte de África. Aun así la participación de Al Qaeda en el Magreb Islámico $\left(\mathrm{AQMI}^{21}\right)$ y el Movimiento por Monoteísmo y Yihad en África Occidental (Mujao), entre otros, en el contrabando de drogas se da por sentado. Funcionarios gubernamentales malienses y franceses han recurrido cada vez más a describir a su adversarios en el norte de Malí como "narco-jihadists'. Sin embargo, estos vínculos no parecen ser generalizados aunque sí que hay una tendencia, tal como advertían Dadurand y Chin, a que grupos de diferentes organizaciones terroristas se estén convirtiendo en grupos de crimen organizado. Además, la corrupción gubernamental en el área favorece esta dinámica. Según Beatriz Mesa, los diferentes grupos terroristas que han dominado el norte de Mali, implantando un sistema similar al talibán a las puertas de Europa, han pretendido, mediante el uso de la violencia, no sólo implantar la ley islámica sino controlar el mercado de la droga ${ }^{22}$. Según este análisis, la droga se ha convertido en el motor económico de toda la región y los réditos económicos generados a raíz del narcotráfico han provocado el hundimiento de Mali, hasta convertirlo prácticamente en un Estado fallido. Junto con los secuestros, la alta rentabilidad del narcotráfico hace que se convierta en "una de las líneas de financiación para la adquisición de armas, vehículos, teléfonos por satélites, entre otros". Esto también ha creado una red clientelar, que como señala Mesa "han logrado afianzar una red de simpatizantes extendidos en todo el Magreb, que orbitan a su alrededor, y funcionan como activistas de la causa, informadores para las operaciones o suministradores de logística"23. El nexo del terrorismo y el crimen organizado se debe reconocer en los círculos políticos como un alto nivel de amenaza a la seguridad internacional.

El nexo entre estas organizaciones debilita estados y crea estados fallidos, creando numerosos espacios sin gobierno, peligrosos, donde los criminales y terroristas pueden $\operatorname{prosperar}^{24}$. La financiación del terrorismo a través del crimen organizado hace que sea más

\footnotetext{
${ }^{18}$ Dandurand Yvon and Chin Vivienne: "Links between terrorism and Other Forms of Crime". International Centre for Criminal Law Reform and Criminal Justice Policy, en $\underline{\text { www.icclr.law.ubc.ca/.../LinksBetweenTerrorismLatest_updated.pdf }}$

${ }^{19}$ Dandurand Yvon and Chin Vivienne, op. cit., p.32.

${ }^{20}$ Véase Wolfram Lacher: "Challenging the Myth of the Drug-Terror Nexus in the Sahel". WACD Background Paper No. 41. 2013.

${ }^{21}$ Al Qaeda del Magreb Islámico (AQMI), anteriormente conocido por Grupo Salafista para la Predicación, es una organización que se crea en el año 1997, de origen argelino, como escisión del denominado Grupo Islámico Armado. Desde sus inicios ha sido vinculado con la Yihad Islámica, y en el año 2006 se vinculó con Al Qaeda. AQMI sigue siendo, principalmente en Argelia, una entidad criminal, donde las conexiones entre grupos armados, ex-combatientes, señores de la guerra, y milicias, se encuentran en un punto de unión entre la delincuencia y el terrorismo. Ammour, Laurence Aïda: "Les défis de sécurité dans la zone saharo-sahélienne et leurs répercussions dans la región méditerranéenne", Ponencia presentada en el IX Seminario Internacional sobre Seguridad y Defensa en el Mediterráneo. Una visión compartida para el Mediterráneo y su vecindad, organizado en Barcelona por CIDOB y Ministerio de Defensa. (25 de octubre de 2010) en:

http://www.sedmed.org/analisis_ssm/documents/semIX/laurence_aida_ammour.pdf

22 "Desde que el yihadismo se asentó en el desierto saheliano -hace en torno a siete años-la mayor preocupación en el seno del grupo terrorista de Al Qaeda-nacido del antiguo GSPC argelino-era el reparto del negocio de la droga. Ésta es la principal fuente financiera que procede de la delincuencia y con la que se ha sufragado la yihad". Beatriz Mesa García. "La Falsa Yihad ¿A qué tipo de amenaza se enfrenta Europa en la Frontera Sur?" IEEE. Documento de Opinión. 21/2013. 5 marzo de 2013.

${ }^{23}$ Ibid. Pp.4-6. Para una revisión más completa véase Mesa, Beatriz (2013): La Falsa Yihad, El negocio del narcotráfico en el Sahel, Ediciones Dalya, Cadiz.

24 "Drug smuggling into Europe 'finances Jihad terrorism', say Spanish authorities", 18/2/2015, en news.gnom.es.
} 
difícil de derrotar, los terroristas pueden tener acceso a las armas más letales, lo que les permite cuestionar y destruir las fuerzas policiales y militares con el equipo de armamento e inteligencia más avanzada. La capacidad de los cárteles del crimen organizado para llevar a cabo el contrabando y la trata de personas permite a los terroristas camuflarse operativos en áreas objetivo clave. Por último, los cárteles del crimen organizado en la mayoría de los casos consiguen más poder cuando cooperan con terroristas. Al terrorismo internacional sólo se le puede ganar con eficacia si las estrategias de lucha contra el terrorismo de los estados tienen en cuenta esta simbiosis cada vez mayor. Para abordar este nexo de forma más eficaz, las instituciones dedicadas a la lucha contra el terrorismo y la delincuencia organizada deben de cooperar más estrechamente y desarrollar nuevas respuestas múltiples para satisfacer estas nuevas amenazas a nivel nacional, regional y mundial ${ }^{25}$. Probablemente la creación o fusión de organizaciones bajo mecanismos de agencia, mucho más flexibles y preparados, con aproximaciones comprehensivas (comprehensive approach) es probablemente la solución.

Figura 1

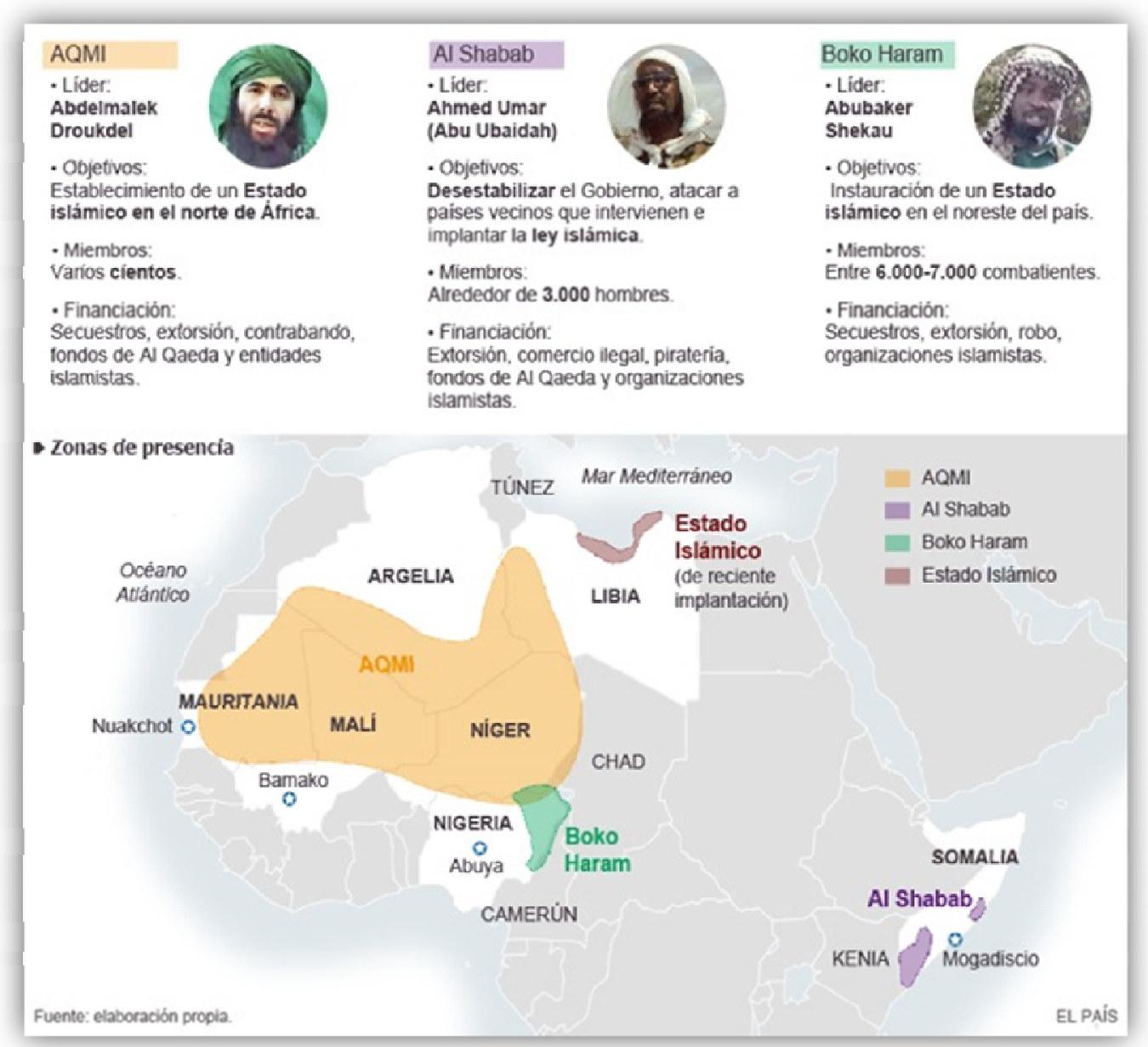

Fuente: El País.

\footnotetext{
${ }^{25}$ Schori Liang, Christina: Shadow Networks: The Growing Nexus of Terrorism and Organized Crime. GCSP Policy Paper n²0, Septiembre 2011.
} 
En este sentido la unión de espacios subgobernados, crimen organizado y terrorismo sería la amenaza a la que nos enfrentaríamos en el Gran Magreb-Sahel ${ }^{26}$ (véase Figura1). Durante la última década se han informado sobre la expansión de las redes del narcotráfico originadas en Suramérica hacia la costa occidental africana, con el fin de llegar al mercado europeo, y que a su vez se han ido desplazando hacia los Estados que se ubican en el Sahel y el Magreb, caracterizados por su fragilidad institucional y democrática. El enfoque con el que se ha abordado esta problemática por parte de los Estados africanos así como los europeos, ha sido criticado por expertos y académicos, puesto que las operaciones e intervenciones han sido orientadas exclusivamente hacia la lucha contra las acciones terroristas perpetradas por grupos islamistas, y no contra las redes del narcotráfico, convirtiéndose en fuentes de financiación de los grupos terroristas, y han ampliado las redes de tráfico de armas y otras actividades delictivas. ${ }^{27}$

\section{Radiografía del Crimen Organizado en el Gran Magreb- Sahel}

\subsection{La región: Seguridad y crimen organizado en el Gran Magreb-Sahel}

El crimen organizado trasnacional es un negocio rentable: se estima que en el año 2009 generó 870 miles de millones, esto es el 1,5\% del PIB mundial. Es más de seis veces de la cantidad de asistencia oficial para el desarrollo correspondiente a ese año, y equivale a casi el $7 \%$ de las exportaciones mundiales de mercancías ${ }^{28}$. Para entender la dimensión del problema, podemos fijarnos en los siguientes datos: un 5\% de la población mundial entre 15 y 64 años han consumido alguna sustancia ilícita durante el año 2012 ${ }^{29}$; entre 2010 y 2012 se identificaron víctimas de trata de seres humanos de 152 nacionalidades diferentes en 124 países de todo el mundo ${ }^{30}$. Según la ONU, la "corrupción es un fenómeno social, politico y económico complejo que afecta a todos los países. La corrupción socava las instituciones democráticas, frena el desarrollo económico y contribuye a la inestabilidad gubernamental. La corrupción ataca los cimientos de las instituciones democráticas mediante la distorsión de los procesos electorales, pervirtiendo el estado de derecho y la creación de atolladeros burocráticos cuya única razón de ser es la solicitación de sobornos". Otros nuevos tipos de crimen, como el cibercrimen, los crímenes contra la identidad, el tráfico en la propiedad cultural, los crímenes medioambientales, la piratería o el tráfico de órganos, también están capitaneados por principales redes criminales. A este respecto, todas estas cifras, forman parte de un conglomerado de amplias actividades delictivas ${ }^{31}$ que realizan los principales grupos de crimen organizado transaccional a lo ancho del globo.

\footnotetext{
${ }^{26}$ Hansen. Wibke: "The Failed State-Organized Crime-Terrorism Nexus". SWP Comments 40.December 2011. http://www.swp-berlin.org/fileadmin/contents/products/comments/2011C40 hansen ks.pdf ; Sobre todo Alda, Erik and Sala, Joseph L.: "Links between Terrorism, Organized Crime and Crime: The Case of the Sahel Region". Stability. International Journal of Security \& Development, 3(1): 27, 2014, pp. 1-9.

${ }^{27}$ Campo, Nicolás: "La seguridad en el diálogo birregional entre Sudamérica y África". IED, 2014.

${ }^{28}$ Oficina de las Naciones Unidas contra la Droga y el Delito, Estimación de las corrientes financieras ilícitas provenientes del tráfico de drogas y otros delitos organizados transnacionales: informe de investigación (Viena, octubre de 2011). UNODC. Delincuencia organizada transnacional - La economía ilegal mundializada en: http://www.unodc.org/documents/toc/factsheets/TOC12 fs_general_ES_HIRES.pdf

${ }^{29}$ Informe Mundial Sobre Drogas 2014. 26 de junio de 2014. Viena. UNODC.

${ }^{30}$ Informe Mundial Sobre Trata de Personas. UNODC. 2014, en https://www.unodc.org/documents/data-andanalysis/glotip/GLOTIP14_ExSum_spanish.pdf

${ }^{31}$ Estas actividades han sido catalogadas por la ONU, en 11 tipologías de crimen: 1 - Actos que conducen a la muerte o tengan intención de causar la muerte; 2 - Actos que llevan a dañar o la intención de causar daño a la persona; 3 - Actos delictivos de naturaleza sexual; 4 - Actos contra la propiedad que supongan violencia o amenaza contra la persona; 5 - Actos contra la propiedad privada; 6 -Actos en los que intervengan sustancias psicoactivas u otras drogas; 7 - Actos de fraude, engaño o corrupción; 8 - Actos contra el orden público, la
} 
En este sentido, la delincuencia organizada transnacional está atrayendo mayor atención debido a que, en el pasado el problema era sobre todo nacional (mafia, mafiya, cárteles, tríadas), ahora, como resultado de la globalización, representa una amenaza a la seguridad internacional ${ }^{32}$. Ningún país está a salvo de esta amenaza.

En términos comparativos con otros continentes, quizá el continente donde la situación es la más traumática sea África. A lo largo y ancho del continente africano se conjuga su idiosincrasia (enormes dificultades en términos políticos, económicos o sociales ${ }^{33}$ ) con un gran vacío de poder generalizado, además de regímenes dictatoriales y altamente corruptos, y donde las organizaciones criminales forjan vínculos entre ellas: bandas criminales, grupos terroristas, grupos rebeldes y estados fallidos ${ }^{34}$, que copan diversos tipos de actividades delictivas: tráfico de armas (alimentado por el sinfín de conflictos y guerras olvidadas); control de los recursos y tráfico de materias primas como piedras preciosas, marfil, oro, platino, madera, petróleo (presentes en el subsuelo de África Occidental y Central), donde se produce una lucha encarnizada por el control de estos yacimientos, que presuntamente desvían fondos a la financiación de actividades terroristas ${ }^{35}$. Por otro lado, el tráfico de seres humanos, donde países productores de petróleo como Gabón, Mauritania, Guinea Ecuatorial, o Sudáfrica y Nigeria, reclutan numerosos emigrantes sub-saharianos que son explotados como mano de obra, incluyendo niños a sus filas. En lo que respecta al narcotráfico, se ha producido en los últimos años, la inclusión de algunas de sus costas y puertos, principalmente de África Occidental entre las ciudades más importantes del paso de drogas, en particular del tránsito trasatlántico de cocaína ${ }^{36}$, como se desarrollará en el apartado de las tramas del crimen.

De igual modo, la región del Magreb es una zona estratégica no solo por su posicionamiento en términos geopolíticos, sino principalmente debido a su proximidad geográfica a Europa, su relevancia política y cultural, su potencial económico y comercial ${ }^{37}$, así como por la existencia de amplias e importantes comunidades magrebíes en multitud de países de la Unión Europea.

Es indiscutible el papel que juega la región del Magreb en la estabilidad de Europa y del Mediterráneo (en términos de seguridad lo que se denomina como flanco sur). No obstante, en

autoridad; 9 - Actos contra la seguridad pública y la seguridad del Estado; 10 - Actos contra el medio ambiente; 11 - Otros actos criminales no clasificados.

${ }^{32}$ Crime and instability Case studies of transnational threats. UNODC. Febrero 2010, en https://www.unodc.org/documents/dataandanalysis/Studies/Crime_and instability 2010 final_26march.pdf

${ }_{33}$ Mazzitelli Antonio L. El desafio de las drogas, el crimen organizado y el terrorismo en África Occidental y Central ARI No 43-2006.

34 "La amenaza para la paz y la seguridad regional no se debe, [...] a la presencia de un estado especialmente fuerte y dominante en una región, sino todo lo contrario, a la debilidad e incluso inexistencia de una estructura estatal". Albares, José Manuel. "Trabajar con socios difíciles: la promoción del desarrollo en los estados frágiles". ARI $N^{o} 18-2005$. (4 de febrero de 2005), en

http://www.realinstitutoelcano.org/wps/portal/rielcano/contenido?WCM_GLOBAL_CONTEXT=/elcano/elcano es/zonas es/cooperacion+y+desarrollo/ari+18-2005.

$\overline{35}$ En Mazzitelli, Antonio L. El desafio de las drogas, el crimen organizado y el terrorismo en África Occidental y Central, p. 17. Links grupos terroristas como Hezbolla en el Líbano, o Al-Qaeda (inversiones en la industria del diamante en Sierra Leona), financiados con fondos procedentes de las explotaciones de diamantes en África. En el caso del petróleo: Nigeria desvía a oleoductos ilegales entre 60.000 y 100.000 barriles de petróleo diarios.

${ }^{36}$ Ibid.

${ }^{37}$ España tiene estrechos vínculos económicos con los países de la región, y especialmente con Marruecos, país del que fuimos primer socio comercial entre enero y septiembre de 2014, y Argelia, con el que también alcanzamos esta posición de primer socio comercial en el año 2013. Además, Argelia es nuestro principal suministrador de gas natural, con el $45 \%$ del aprovisionamiento. 
lo que respecta al ámbito exclusivo de la seguridad, el gran Magreb y el Sahel ${ }^{38}$, suponen hoy un foco de inestabilidad y un territorio con constantes actuaciones de importantes redes de crimen organizado trasnacional. Al albur de los últimos acontecimientos, esta amenaza se ha expandido e implantado con mayor vigor en muchos de los principales países de la región: Libia, Argelia, y Marruecos, así como en algunos de los países del Sahel.

A este respecto, los cambios políticos que se iniciaron con la denominada 'Primavera Árabe ${ }^{, 39}$ en los países anteriormente mencionados han provocado fuertes tensiones, principalmente en Libia, tras la muerte de Gadafi, pero también en el resto de países. En particular, las amenazas existentes en el Magreb y en parte del Sahel afectan directamente a la seguridad europea: la amenaza terrorista, el tráfico de estupefacientes y de armas, el crimen organizado o las redes de tráfico de seres humanos, y el fenómeno conocido como narcoterrorismo, son problemas que hoy forman parte de la agenda no europea, puesto que el destinatario final de todo lo "que se moviliza de forma ilegal o irregular" en la región, es la Unión Europea, principalmente los países de la ribera del Mediterráneo: España e Italia y en menor medida Francia y Grecia. Asimismo es necesario destacar que la ausencia de control en las fronteras en el Magreb y el Sahel dinamita la estabilidad regional, que, unido a una serie de características propias de la región, hacen que el crimen organizado sea una de las principales amenazas para la seguridad, principalmente europea, pero también internacional.

Esta primera aproximación a la región pretende definir y acotar, por un lado, los países que serán objeto de estudio en el presente artículo: Marruecos, Argelia y Túnez ${ }^{40}, \mathrm{y}$, por otro lado Libia, puesto que en el tema que nos ocupa, crimen organizado, Libia lidera de algún modo la presencia de redes de crimen organizado, principalmente debido a su situación de inestabilidad y desgobierno. Del mismo modo, este artículo hará referencia al Sahel, puesto que en lo que a crimen organizado trasnacional se refiere, es relevante en tanto en cuanto la inexistencia de controles y de autoridad reconocible, la porosidad y apenas presencia de fronteras, así como la corrupción endémica existente en el seno de la mayoría de estos estados, que permiten la actuación de las redes de contrabando de forma impune a lo largo y ancho del Magreb y del Sahel.

En definitiva, entre las causas subyacentes que facilitan la actividad de grupos de criminalidad organizada en esta zona se encuentran, entre otras: la pobreza endémica; el descontento de las poblaciones de zonas remotas con la falta de servicios ofrecidos por los gobiernos estatales; la existencia de enormes fronteras, trazadas artificialmente durante la época colonial, que los estados son incapaces de controlar; el impacto de conflictos ajenos a la región, como el israelí-palestino y la invasión de Irak de 2003 y más recientemente el conflicto en Siria; la falta de una democracia creíble y la opresión sobre determinados

\footnotetext{
${ }^{38}$ La región del Sahel se es un amplia área semidesértica muy escasamente poblada, cuya extensión se extiende al sur del Sáhara desde Mauritania hasta Sudán con cerca de 4 millones de kilómetros cuadrados entre los que se encuentran Mauritania, Senegal, Mali, Argelia, Guinea, Burkina Faso, Níger, Nigeria, Camerún, Chad, Sudán, Eritrea y Somalia. Perianes Bermúdez, Ana Belén, "Desafíos para la seguridad española respecto a la inestabilidad en el Sahel". Panel Grupo 9: Seguridad en África Subsahariana. IUGM. En http://estudiosmilitares.es/comunicaciones/Ana\%20Belen $\% 20$ Perianes $\% 20$ Berm $\% \mathrm{C} 3 \%$ BAdez.pdf

${ }^{39}$ Lo que se ha denominado como 'Primaveras Árabes' son una serie de alzamientos populares acaecidos en los países árabes desde el año 2010 hasta la actualidad. Los países que han protagonizado este tipo de movimientos son: Túnez, Argelia, Mauritania, Arabia Saudí, Omán, Yemen, Libia, Líbano, Kuwait, Sudán, Jordania, Siria, Egipto, Irak, Irán, Marruecos así como en los territorios de Palestina y del Sáhara Occidental. Cabe destacar que la incidencia de estos movimientos no ha sido igual en todos los países. Por un lado Túnez, celebró, a finales de 2014 elecciones legislativas y presidenciales, culminando así la transición política y convirtiéndose en el primer país árabe que elige por sufragio universal y directo a su jefe de Estado. Por otro lado, Marruecos y Argelia han atendido las demandas populares emprendiendo programas de reformas.

${ }^{40}$ Sayigh, Yezid: "Missed opportunity. The politics of police reform in Egypt and Tunisia". Carnegie Middle East Center (marzo de 2015), en http://carnegie-mec.org/publications/?fa=59391.
} 
colectivos $^{41}$; la corrupción generalizada y endémica que asola las instituciones; el vínculo clave entre terrorismo y crimen organizado, en actividades como el contrabando y el blanqueo de dinero. Este último punto, y la conexión existente entre terrorismo y crimen organizado, como se ha desarrollado anteriormente, en otro epígrafe del presente artículo. Para ello, es necesario, en primer lugar, tomar conciencia sobre las capacidades de cooperación creciente entre los grupos terroristas de la región, tal y como ha quedado demostrado en la introducción.

En ciertos aspectos puede interpretarse que, tanto los grupos terroristas que operan en la región como los dedicados al crimen organizado, buscan, entre otras cosas: suplantar al estado en las zonas carentes de gobernación; provocar la caída de los gobiernos locales; y, por último, y de modo colateral, amenazar los intereses occidentales. A este respecto la respuesta a la amenaza tanto del crimen organizado trasnacional o el terrorismo en el Magreb, no pueden ser combatidos exclusivamente en términos nacionales, y se debe, por tanto, diseñar un escenario geográfico, estratégico y temporal a medio y largo plazo, con una visión holística de la geopolítica de la región ${ }^{42}$. Es necesario por tanto que los principales actores implicados inicien un proceso de cooperación en materia de seguridad, puesto que este tipo de amenazas requiere unas capacidades conjuntas para poder hacer frente a una amenaza tan potente y extendida. Este tipo de iniciativas serán tratadas en el punto dos del presente artículo de forma extensa, identificando y analizando la eficacia de las principales actuaciones a nivel nacional, regional e internacional para luchar contra el crimen organizado en el Magreb y el Sahel.

El siguiente mapa permite visualizar las causas descritas anteriormente, esto es, la relación directa que existe entre la debilidad de los estados, la permeabilidad de las fronteras y el tráfico de drogas, y cómo estos elementos estructurales son una pieza clave para entender las actividades ilícitas en la zona.

Figura 2

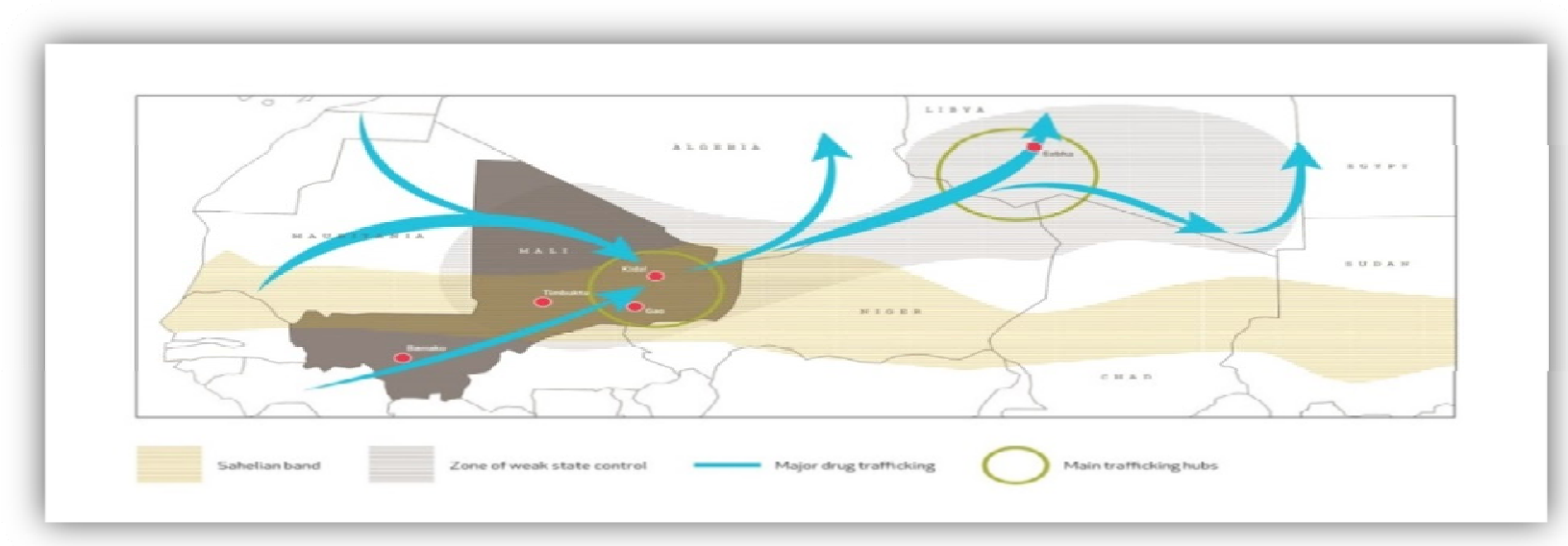

Fuente: Potomac Institute 2011.

\footnotetext{
${ }^{41}$ Según el PNUD, actualmente, "the Arab States stand at a crossroads between progress and desire for change, and faltering development and crisis. Recent MDG progress has slowed. The transition that began with high hopes in 2011 has brought gains in some countries but taken a terrible toll in others". PNUD: 2013-2014 Annual Report. New Partnerships for Development, en http://www.undp.org/content/dam/rbas/report/UNDP AR2014 english.pdf

${ }^{42}$ Ver: Mattes, Hanspeter. "Domestic Security in the Maghreb: Deficits and Counter-Measures". GIGA working papers. $N^{o}$ 186. (Enero de 2012), en https:/www.giga-hamburg.de/de/system/files/publications/wp186 mattes.pdf
} 


\section{2. - Las tramas del crimen organizado en el Sahel}

Esta región, ya desde la Edad Media, fue un foco relevante en lo que respecta al control de las rutas de comercio por las que transcurría el tráfico de mercancías como el oro, la sal o los esclavos $^{43}$. Esta situación se vio reducida durante los años de ocupación colonial por parte de Francia, para ser retomada tras la independencia, en particular desde Argelia y Libia a los países de reciente creación como Malí y Níger. En este sentido, los anteriores productos han sido sustituidos por drogas, seres humanos y armas.

A continuación se van a detallar las especificidades de los países de la región en cuanto al crimen organizado se refiere, tanto en el Magreb, como en el Sahel, con las particularidades de los países que lo conforman. A pesar de esta acotación, no es óbice para que a lo largo del artículo se haga alusión a otros países del continente africano en los que confluyan las amenazas que estamos analizado: el crimen organizado por un lado, y sus vínculos con el terrorismo, por otro.

Es un hecho incontestable que se está produciendo un desgaste estructural de la seguridad de África del Norte, con posibles consecuencias para el Mediterráneo y el África sub-sahariana ${ }^{44}$. Del mismo modo, "casi todos los países de la zona tienen dificultades para hacer frente a las actuaciones del crimen organizado, el terrorismo yihadista o la insurgencia en sus territorios, con lo que son sensibles - cuando no vulnerables- a la actuación de esos grupos, lo que les abona a una situación de fragilidad o fallo latente" ${ }^{45}$.

Del mismo modo, el siguiente mapa muestra en detalle las redes de tráficos ilícitos, por un lado el tráfico de personas y la inmigración ilegal, punta de lanza de las principales actuaciones por parte de la Unión Europea en la actualidad ${ }^{46}$; por otro, las rutas de contrabando de armas, tabaco y drogas (cannabis y cocaína); y el tráfico de armas desde la caída del régimen libio. El mapa asimismo muestra más información sobre los principales asuntos que generan inestabilidad en esa área geográfica, como la existencia de conflictos armados, o las áreas de actividad de organizaciones como Boko Haram, AQMI o el colectivo de los tuareg ${ }^{47}$.

En definitiva, el Norte de África en su conjunto se ha convertido en una zona del mundo donde los grandes conglomerados del crimen organizado trasnacional han encontrado un ambiente particularmente favorable para llevar a cabo su actividad, en regiones con gobiernos débiles, donde el estado es demasiado pobre para ejercer la autoridad, o bien donde grupos

\footnotetext{
${ }^{43}$ Fuente Cobo, Ignacio. "La amenaza híbrida: Yihadismo y crimen organizado en el Sahel". IEEE. № 57/2014. (3 de diciembre de 2014). P. 3. En http://www.ieee.es/Galerias/fichero/docs_analisis/2014/DIEEEA572014_AmenazaHibridaSAHEL_IFC.pdf

44 Ruiz González, Francisco José. "Desarrollo del Segundo "Marrakech Secutiry Forum". Documento informativo del IEEE. No 03/2011. (Enero de 2011). En http://www.ieee.es/Galerias/fichero/docs informativos/2011/DIEEEI032011SegundoMarrakechSecurityForum.pdf

${ }^{45}$ Arteaga, Félix. "España mirando al Sur: del Mediterráneo al Sahel". Informe Elcano (noviembre 2014. en:http:/www.realinstitutoelcano.org/wps/wcm/connect/349a5b80467ff303b17db7bdae0ed545/InformeElcano1 $\underline{8}$ Espana_mirando_al_sur_mediterraneo_sahel.pdf?MOD=AJPERES\&CACHEID=349a5b80467ff303b17db7b dae0ed545

${ }^{46}$ La UE ha puesto en marcha diversas iniciativas (desarrolladas en el aparatado 2.2 del presente artículo) desde el inicio de oleadas de inmigrantes ilegales a las costas de los países miembros de la ribera del Mediterráneo: España, e Italia y en menor medida Grecia. Este hecho se desarrollará en el capítulo específico sobre tráfico de personas en la región del Magreb.

47 Para más información: Moraleda Martín-Peñato, Manuel. "El pueblo tuareg y su papel en el conflicto de Mali". IEEE. Documento de opinión No75/2013. (14 agosto de 2013) en:

http://www.ieee.es/Galerias/fichero/docs_opinion/2013/DIEEEO75-2013 Tuaregs_MMoraleda.pdf
} 
insurgentes han asumido algún grado de control y ejercen un poder alternativo en determinados territorios (véase Figura 3).

Figura 3

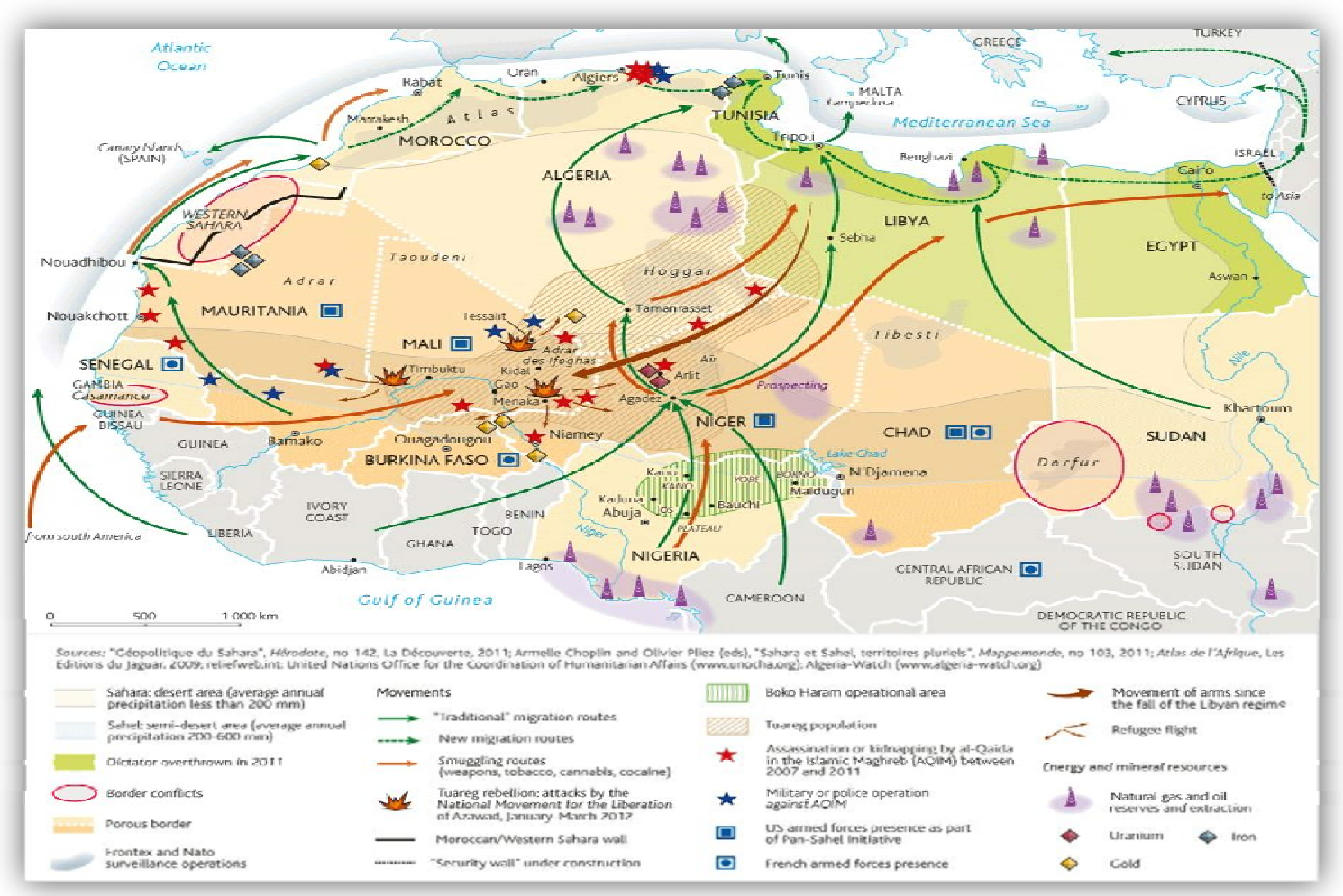

Fuente: Elordenmundial.org.

Como se ha demostrado, la región del Gran Magreb es un lugar perfecto para que las principales organizaciones criminales transnacionales tengan cierta importancia y realicen diversas actividades. Cabe destacar que, en el caso del tráfico de drogas, la droga proveniente de América Latina, llega a Europa vía África Occidental, y tiene su origen en Venezuela, Brasil, Colombia, así como en menor medida México.

A continuación se explicará lo que se ha denominado la 'ruta del Sahel' de la droga, que, con algunas variaciones de itinerario, esta zona se ha convertido en una ruta primordial para el contrabando. En cuanto a la forma de acceso de las diversas drogas, y de acuerdo con las informaciones que apuntan a una modificación de las rutas y de la forma de proceder por parte de los traficantes, así como en lo que respecta a los emplazamientos de los grupos criminales, es necesario subrayar una serie de cambios que se han producido en lo que a las rutas del transporte de la droga se refiere. En este sentido, históricamente las principales rutas de la droga proveniente de América Latina, realizaba una ruta exclusivamente trasatlántica, esto es, desde el Caribe, alcanzaba los puertos de Holanda o de la Península Ibérica, vía los archipiélagos de Azores, Madeira y Canarias. Esta modificación en la ruta de la droga es debida principalmente a la mejora de la acción policial, una mayor eficacia y un aumento de la vigilancia en los países históricamente receptores. Así, las redes del narcotráfico han virado, buscando rutas menos directas pero a la vez con menor control, en particular, poniendo su foco de acceso en la fachada atlántica de África Occidental. Cabe destacar que si bien aparentemente traficar vía África Occidental incrementa los riesgos para los grupos 
delictivos (mayor número de kilómetros y mayor número de países de tránsito), a largo plazo sí se considera que existen ciertas ventajas sobre las rutas más directas. De este modo, los grupos criminales sudamericanos han establecido su presencia de forma nítida en varios estados tales como Cabo Verde o Guinea Bissau, debido a las idiosincrasias compatibles entre los traficantes sudamericanos y sus contrapartes africanos-occidentales ${ }^{48}$.

En el siguiente mapa, se especifican las rutas de las organizaciones y grupos criminales una vez que la droga ya se encuentra en el continente africano. Así, con procedencia del Norte de África, existen fundamentalmente dos rutas: una por Nigeria a través de Senegal y Marruecos, y otra por Níger, Argelia y Marruecos, cuyo destino final es España (véase Figura 4).

Figura 4

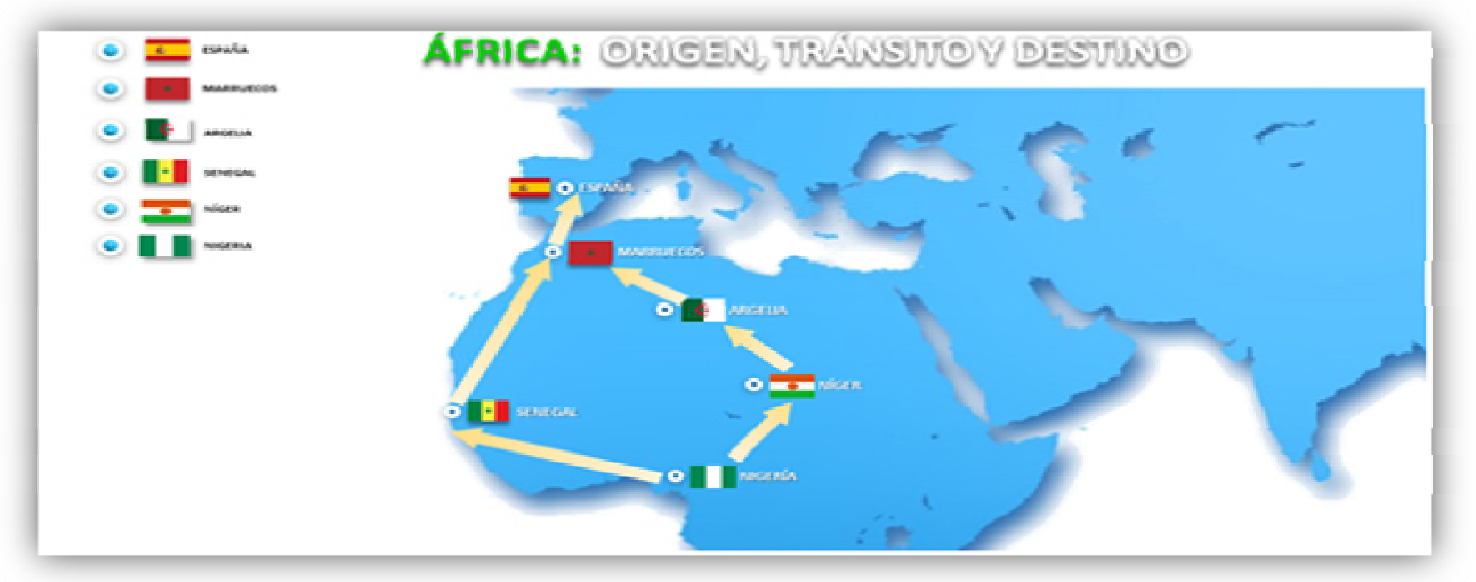

Fuente: LaMoncloa.org.

En este sentido, las conexiones entre el Magreb y el Sahel (situación de Mali, la caída de Gadafi en Libia o las redes de crimen organizado transfronterizas) y entre el Magreb y Oriente Medio (por ejemplo con la abultada presencia de los combatientes magrebíes en Siria) son evidentes ${ }^{49}$ y deben ser combatidas conjuntamente.

Así, la primera 'parada de la droga' son las islas de Guinea Bissau, Senegal o Mauritana, y posteriormente, desde donde posteriormente se traslada la cocaína procedente de Latinoamérica a un gran triangulo de tierra de nadie entre el norte de Malí y Níger, el sur de Libia y Argelia y el este de Mauritania. Adicionalmente los narcotraficantes utilizan también

\footnotetext{
${ }^{48}$ Philip de Andrés, Amado: "West Africa Under Attack: drugs, organized crime and terrorism as the new threats to Global Security". UNISCI Discussion Papers, No 16 (Enero / January 2008) en https://www.ucm.es/data/cont/media/www/pag-72513/UNISCI\%20DP\%2016\%20-\%20Andres.pdf.

${ }^{49}$ En la actualidad, hay combatientes terroristas extranjeros procedentes de más de la mitad de los países del mundo. Entre los diferentes asociados de Al-Qaida (QDe.004) alrededor del planeta, incluido el grupo disidente Estado Islámico de Iraq y el Levante (EIIL) (que figura en la Lista como Al-Qaida en el Iraq (QDe.115), hay más de 25.000 combatientes terroristas extranjeros, que provienen de más de 100 estados miembros. El número de personas que viajan con este fin es más alto que nunca antes, y los principales destinos son la República Árabe Siria y el Iraq, además de Libia, donde este problema también va en aumento. Los datos corresponden al Informe sobre los combatientes terroristas extranjeros elaborado por el Equipo de Apoyo Analítico y Vigilancia de las Sanciones establecido en virtud de la resolución 1526 (2004), que se presentó al Comité del Consejo de Seguridad dimanante de las resoluciones 1267 (1999) y 1989 (2011) relativas a Al-Qaida y las personas y entidades asociadas. conforme a lo dispuesto en el párrafo 23 de la resolución 2178 (2014). Consejo de Seguridad de la ONU. 19 de mayo de 2015, en http://www.un.org/en/sc/ctc/docs/2015/N1508460 ES.pdf.
} 
pistas de arena en el desierto para que aterricen aviones cargados de sustancias ilegales, donde no puedan ser detectados pos los radares.

En el mismo orden de cosas, cabe destacar que los vuelos con correos humanos son otro método de introducción de drogas, si bien a una escala menor. De acuerdo con las cifras del Ministerio del Interior, en el año 2012 un total de 1.679 personas fueron detenidas en 2012 por esta práctica. Así, de la cocaína incautada el año pasado, la mayor carga, más de 7,5 toneladas fue trasladada mediante buques en alta mar, y un 4,2, toneladas fueron interceptadas en contenedores en los propios puertos.

Del mismo modo, Marruecos, un estado estable para llevar a cabo negocios se ha convertido en otro de los países de destino de la droga, junto con Libia, que, tras la caída del régimen de Gadafi, ofrece grandes facilidades como ya se ha señalado anteriormente. Así, los narcos fletan barcos desde el puerto de Misrata con destinos variados como Malta, Nápoles, Valencia o Barcelona. Cabe destacar que en determinados países como Italia, los grandes cárteles colombianos se han aliado con las mafias locales, como la Camorra y otros grupos, consiguiendo mejorar así sus capacidades, al utilizar tanto rutas como medios, así como la infraestructura previamente existente, realizando operaciones mucho mejor organizadas y por tanto mayormente exitosas.

Esta realidad se sustenta en una serie de factores, que, contribuyen a hacer del norte de África una zona propicia para que el crimen anide: la escasa competencia en cuanto a mecanismos de lucha y recursos tecnológicos de los conglomerados del crimen respecto a las autoridades de la zona. En este sentido, basta con comparar los medios de vigilancia y el nivel de tecnología de que dispone Europa Occidental con los de África. Otro punto a subrayar, es el nivel de corruptibilidad de autoridades, jueces y policía, en un caso y en otro. En este tema en particular, el bajo nivel y condiciones de vida, así como la pobreza y los bajos salarios, facilitan que la capacidad de sobornar sea mayor en la región africana. Otros aspecto es la vasta extensión de territorio en el caso de África, y la competencia de los recursos de las fuerzas del orden dado el amplio número de países implicados en la seguridad de la zona, y, por el contrario, el grado de capacidades y mecanismos, así como un territorio mucho más controlable en el caso de Europa que en el de África ${ }^{50}$.

En este sentido, el norte de África y algunos países de la franja del Sahel se han convertido en un área ideal para poner en práctica la división y el almacenaje de la droga en puntos muy diversificados en el espacio, lo que es altamente rentable a la hora de realizar el reenvío de la droga a los países de destino final. La droga es por tanto almacenada en estos países para luego emprender un nuevo viaje a los países europeos ${ }^{51}$.

\section{3. - Las actividades del crimen organizado en la región}

En cuanto a las actividades del crimen en la zona, estas son de muy variada índole: tráfico de drogas, tráfico de armas, tráfico de seres humanos, principalmente, $\mathrm{y}$, en menor medida, crimen contra la propiedad intelectual y falsificaciones, lavado de dinero, delitos de estafa y fraude.

A continuación, vamos a centrarnos en una de las principales actividades que lleva a cabo el crimen organizado en esta zona del mundo: el tráfico de drogas. En este sentido, la

\footnotetext{
50 Pérez, Jesús: "Un Flanco Sur Profundo. El arco de inestabilidad de África Occidental". III Congreso Internacional de Seguridad y Defensa. Granada. (Noviembre 2008).

${ }^{51}$ Arteaga, Félix: "España mirando al Sur: del Mediterráneo al Sahel". Informe Elcano. (Noviembre 2014), en http://www.realinstitutoelcano.org/wps/wcm/connect/349a5b80467ff303b17db7bdae0ed545/InformeElcano18 Espana_mirando_al_sur_mediterraneo_sahel.pdf?MOD=AJPERES\&CACHEID=349a5b80467ff303b17db7bdae $\underline{0 \text { ed545 }}$
} 
existencia de estos grupos viene respaldada por la existencia de un gran volumen de tráfico de drogas entre la zona del Magreb y Europa, asunto que atenta directamente contra la seguridad occidental. En particular, existen datos ${ }^{52}$ que avalan y constatan la existencia de un importante volumen de tráfico de drogas en la región. Cabe destacar que existe cierta relativización del riesgo, principalmente por el proceso de diversificación de las rutas de contrabando. Asimismo la Oficina de Naciones Unidas para la Droga y el Crimen Organizado (UNODC) pone de manifiesto los efectos que tanto el consumo como el tráfico de estupefacientes están creando entre la población y la gobernanza de la zona, reforzando las redes criminales organizadas y fomentando la corrupción local, lo que sí afecta de forma directa a la estabilidad regional.

En ciertos países del Magreb y el Sahel queda constatado, de acuerdo con la información publicada por la UNODC que las rutas criminales trasladan cocaína a la costa occidental africana desde América Latina y, por otro, heroína a la costa oriental desde Asia. De esas costas parten redes que distribuyen las drogas de costa a costa y, desde ellas, hacia Europa o Asia, a lo que habría que añadir la distribución de las anfetaminas producidas localmente.

Por otro lado, en África Occidental, la inestabilidad se focaliza principalmente en las subregiones del Golfo de Guinea. La limitada capacidad para aplicar la ley de muchos de los Estados, hacen que en esta región confluyan diferentes amenazas a la seguridad así como problemas estructurales, asociados principalmente a la debilidad inherente de los estados: la pobreza endémica, la piratería, el auge de la presencia del terrorismo yihadista y el incremento del crimen organizado. A este respecto la OCDE identifica estos elementos como importantes obstáculos para el potencial de desarrollo de la región. De este modo, África Occidental se perfila como una vía de acceso a Europa de las drogas que llegan desde América Latina, a modo de $h u b$, donde se prepara la mercancía para el posterior tránsito en países como Guinea, Guinea Bissau, Ghana, Benín, Nigeria y Sierra Leona a los que se han unido Mauritania y Marruecos como nodos necesarios en las redes de contrabando ya que disponen de puertos, aeropuertos y fronteras permeables desde los que canalizar los flujos, con disparidad de direcciones y de acuerdo a las oportunidades del mercado de la droga así como la existencia de menor presión policial ${ }^{53}$.

Es necesario subrayar que las aprensiones de alijos de droga no son en este caso concluyentes como fuente de información, puesto que tanto el origen, como el volumen o los flujos, así como las circunstancias de las incautaciones siempre se encuentran bajo un halo de sospecha por la corrupción endémica existente en la mayoría de esos países ${ }^{54}$. Así, según los datos dispuestos por la UNODC, el tráfico de cocaína entre América Latina y África Occidental se ha ido reduciendo desde el año 2007, relacionado de forma proporcional a la

\footnotetext{
${ }^{52}$ Datos de la Oficina de Naciones Unidas para la Droga y el Crimen Organizado (UNODC) Año 2013. En particular este informe avala esa percepción de existencia de redes criminales y constata la existencia del tráfico, si bien, en menor proporción que la intuida y con tendencia a la baja desde el punto álgido alcanzado en el año 2007. Datos de la UNODC Año 2013. Cabe destacar que la UNODC resalta la falta de fiabilidad de los datos recogidos en el continente africano.

${ }^{53}$ Arteaga, Félix: "España mirando al Sur: del Mediterráneo al Sahel". Informe Elcano. (Noviembre 2014), en http://www.realinstitutoelcano.org/wps/wcm/connect/349a5b80467ff303b17db7bdae0ed545/InformeElcano18 Espana_mirando_al_sur_mediterraneo_sahel.pdf?MOD=AJPERES\&CACHEID=349a5b80467ff303b17db7bdae 0ed545

${ }^{54}$ En particular se considera que se ha producido un cambio en el modus operandi de las redes criminales, y que las aprehensiones de alijos se habrían reducido en tanto en cuanto se han incrementado los grandes envíos por vía aérea y buques mercantes en detrimento de los transbordos y lanchas rápidas interceptadas con drogas. Como se recoge en el Informe de la Junta Internacional de Fiscalización de Estupefacientes del año 2011. JIFE (Junta Internacional de Fiscalización de Estupefacientes), 2012.
} 
disminución del número de incautaciones. En particular: 3 toneladas en 2004, 17 en el año 2005, en 2006, 32 toneladas; en el año 2007, 47; y, posteriormente la cifra va disminuyendo paulatinamente 23 toneladas en el 2008, 21 en el año 2009 y 18 en 2010. Lo que supone un valor de mercado de alrededor de unos 25.000 millones de dólares ${ }^{55}$.

En el tema del hachís es un caso particular, puesto que su producción es endémica en el Norte de África desde hace varias décadas. En particular, la región es productora y emisora indiscutible de esta droga al resto del mundo. Así, el 72\% de la cantidad de resina de cannabis que se incauta en el mundo entero procede de un único país de la región: Marruecos ${ }^{56}$.De este modo, Marruecos es el primer exportador de cannabis del mundo, y esta actividad representa el $10 \%$ del PIB del país. La ruta de abastecimiento se realizaba a través del Estrecho de Gibraltar, y cada año, se incautan en este tramo más de 600 toneladas de droga. Asimismo, el $65 \%$ del hachís incautado por las autoridades en el mundo proviene del país alauita. Cabe destacar que, a pesar de los anunciados esfuerzos por parte de este país en lo que respecta a la disminución de la superficie destinada al cultivo ilícito de cannabis (siendo de 72.500 declaradas en el año 2005, a 47.400 hectáreas declaradas en 2011), la realidad es demoledora: Marruecos continua siendo el primer país productor de cannabis del mundo.

Este esfuerzo de erradicación por parte de Marruecos no es ni válido ni suficiente, puesto que lidera en primer lugar, junto a Afganistán, la producción mundial de cannabis ${ }^{57}$. Del mismo modo, la UNODC, arroja los siguientes datos: el tráfico ilícito de resina y kif de cannabis $^{58}$ se está reduciendo en los últimos años mientras aumenta el tráfico así como la calidad de la hierba de cannabis. En particular, desde las autoridades subrayan que el auténtico problema al que se enfrenta Marruecos, no es exclusivamente en lo que respecta al cannabis, sino a las redes de contrabando de dicha droga, puesto que actualmente las redes de tráfico de drogas de cocaína y heroína, de Latinoamérica y Asia respectivamente, tratan de aprovechar estas redes que habitualmente los traficantes marroquíes venían usando para introducir sus drogas en Europa ${ }^{59}$. De este modo, la incautación de importantes cantidades de droga en los puestos fronterizos, delitos perpetrados en suelo marroquí, han obligado no obstante que, ante esta situación, el Reino de Marruecos se haya comprometido a llevar a cabo una lucha ante cualquier forma de criminalidad organizada, si bien la realidad sigue imponiéndose y a día de hoy, Marruecos es un país donde las redes criminales campan a sus anchas y donde en muchos casos, las autoridades se ven implicadas en operaciones principalmente relacionadas con el tráfico de drogas, en particular con la producción y distribución de cannabis.

En otro orden de cosas, en lo que respecta a la cocaína, donde la demanda europea se encuentra entre 135 y 145 toneladas anuales, Brasil es el principal país de origen, seguido de Bolivia. Ambos emplean aeronaves y buques comerciales para el tráfico de cocaína en contenedores. No obstante la cantidad de cocaína que llega a Europa desde África Occidental, de las 20 toneladas de cocaína aprehendidas en España en el año 2011, esto es, el 40\% de la aprehendida en Europa (menos del 1\%) procedía de allí ${ }^{60}$.

De este modo, la ruta principal que sigue la cocaína hoy desde los países productores se realiza por la denominada 'Autopista 10', que es una línea en el mapa, correspondiente con el paralelo 10, que va desde los países latinoamericanos productores hasta las costas de África.

\footnotetext{
${ }^{55}$ Datos UNODC para el año 2013.

${ }^{56}$ JIFE (Junta Internacional de Fiscalización de Estupefacientes). Año 2014, p. 55.

${ }^{57}$ Según la ONUDD, 89.900 familias viven del cultivo de kif, con un saldo aproximado inferior a los 2.000 euros anuales.

${ }^{58}$ UNODC año 2013, p. 25.

${ }^{59}$ Datos DAVA (Dirección Adjunta de Vigilancia Aduanera). Año 2013.

${ }^{60}$ Datos recabados de la Serious Organised Crime Office (SOCA) en Accra y Daka. EUCRP, Año 2013, p. 152.
} 
De este modo, estados débiles o fallidos como Sierra Leona, Mauritania o Liberia son los preferidos por los carteles de la droga. Del mismo modo, la ONU ha pasado a calificar a Guinea-Bissau como un auténtico narco-estado ${ }^{61}$, puesto que debido principalmente a su orografía (está formado por más de 100 islas, de las cuales 21 tienen aeródromos; tiene 350 kilómetros de costa), es uno de los principales almacenes y lanzaderas de la droga, puesto que es sumamente fácil la llegada, tanto por mar como por aire, de buques y aeronaves cargados de droga. A este respecto, en la denominada autopista 10, el traslado por mar se realiza en barcos que únicamente navegan por la noche, mientras que por el día se mantienen cubiertos con lonas azules, con una media de 4 o 5 días en cruzar el océano Atlántico. En el caso de los traslados aéreos, los mismos se realizan a través de pequeños aviones a los que se les instala depósitos suplementarios para aumentar así su autonomía de vuelo, y que aterrizan en pistas poco vigiladas de los países de África Occidental.

Otro caso anecdótico es lo que se ha denominado como 'Air Cocaine'. En este caso se trata de los cárteles colombianos, los cuales poseen una flota de hasta 8 aviones ${ }^{62}$. El transporte, esto es cargamentos de cocaína que realizan vuelos trasatlánticos cuentan con ex pilotos rusos contratados por los narcotraficantes. Asimismo, en estos países de tránsito, se están construyendo urbanizaciones de narcotraficantes y contrabandistas, como por ejemplo es el caso de Gao en Mali.

Por otro lado, la heroína entra principalmente 'por los puertos y aeropuertos orientales africanos (en torno a 40 toneladas procedentes de Afganistán) según se desprende del crecimiento de las incautaciones de heroína en países como Kenia y Tanzania, si bien se han registrado incautaciones de menor entidad en la costa occidental ${ }^{63}$. Entre 2011 y 2012 se importaron 33 toneladas de cocaína desde América Latina, de las cuales unas 20 se habría destinado a Europa ${ }^{64}$.

En cuanto a las anfetaminas, se ha detectado producción local de esta droga tanto en Nigeria como en Benín, que se han convertido en centros de distribución en la región del Gran Magreb. En Nigeria han sido desmantelados dos laboratorios de estas sustancias estupefacientes desde el año 2011.

En otro orden de cosas otro de los negocios lucrativos a los que se dedica el crimen organizado, con creciente presencia a nivel mundial es el tráfico de seres humanos. La trata de personas supone hoy uno de los principales riesgos para la seguridad de las naciones, y es en la actualidad, junto al tráfico de drogas, una de las actividades ilícitas más lucrativas y en preocupante expansión.

En el Magreb y en Sahel, son continuas las referencias a desarticulación y operaciones en contra de las redes dedicadas a la trata de seres humanos. Se calcula que entre 2010 y 2012 las víctimas de esta lacra, pertenecían a más de 152 nacionalidades y fueron encontradas en más de 124 países $^{65}$. Esto es lo que hace de este asunto algo realmente global. En cuanto a los

\footnotetext{
${ }^{61}$ Llama la atención que Naciones Unidas señalara a Guinea Bissau como el primer "narco estado" africano. Tras la guerra civil de finales de los años noventa, los informes internacionales sobre corrupción y colapso de la administración pública local son significativos. Asimismo las instituciones internacionales han dejado de proveer fondos de ayuda a este estado. Kohnert, Dirk: "Democratisation via elections in an African 'narco state'? The case of Guinea Bissau". Munich Personal RePEc Archive. (Diciembre 2009), en https://mpra.ub.unimuenchen.de/19109/1/Guinea-Bissau-2009-RePEc.pdf

${ }^{62}$ Perdieron un noveno avión, un Boeing 727, en el año 2009, en el Sahel al intentar aterrizar. El aparato tenía los depósitos modificados para llevar a cabo vuelos trasatlánticos.

${ }^{63}$ JIFE Año 2012, p. 56.

${ }^{64}$ Datos de Lapaque, Pierre, representante de UNODC para África Occidental y Central. 23 de julio de 2013, en http//afriquedrogue.blogs.rfi.fr

${ }^{65} \mathrm{http}: / /$ www.unodc.org/documents/human-trafficking/2014/GLOTIP 2014 full_report.pdf
} 
países de la región, existe un claro nexo entre el tráfico de flujos transfronterizos de las víctimas de esta región. En Europa y Asia Central, alrededor de un 9\% de las personas condenadas son de África y Oriente Medio (6\% provenientes del África subsahariana y el 3\% del Norte África y Oriente Medio). Por otra parte, los traficantes de África Occidental fueron detectados en otras partes de África, Oriente Medio y Europa ${ }^{66}$. Cabe destacar que en la región, a pesar de la entrada en vigor del Protocolo de la Trata de Personas, y de que en al año 2012 la mayoría de los países cuenta con una legislación en línea con las normas internacionales. Únicamente dos países, Emiratos Árabes Unidos e Israel, proveen de la información pertinente a los principales organismos internacionales que se ocupan de la materia. Cabe destacar que, en el ámbito de la inmigración, España trabaja en colaboración con los países de la región, para aplicar un enfoque global, que lucha contra la inmigración ilegal y fomenta la inmigración legal.

Cabe destacar que en la mayoría de los casos, las corrientes de trata transfronterizas, de carácter subregional y trans-regional, están vinculadas o son parte de las principales redes de la delincuencia organizada, puesto que la trata de seres humanos de forma compleja puede ser asumida de forma más fácil por grupos delictivos de gran envergadura, y con una estructura bien organizada. A este respecto, en el caso del tráfico de seres humanos, a mayor número de kilómetros que las víctimas de trata son trasladadas, mayores son los costes y los riesgos, y por ende, mayores son las organizaciones. Asimismo, el carácter transnacional de las corrientes, el grado victimización, así como la implicación de un mayor número al mismo tiempo, y el carácter duradero de la actividad delictivita, ofrecen indicios sobre el nivel de organización de la red de trata de seres humanos.

El siguiente mapamundi muestra las corrientes de flujo de seres humanos traficados y las consiguientes subregiones de origen y de destino. A este respecto, se desarrollará en otro artículo de forma más extensa la situación de la inmigración (regular e irregular) en su conjunto, si bien en este artículo nos ceñimos a la trata de seres humanos, que en el caso de la región del Magreb se corresponde con la actuación de grandes redes que operan a gran escala, compitiendo con otras redes de carácter menor que operan a nivel subregional (véase Figura $5)$.

Figura 5

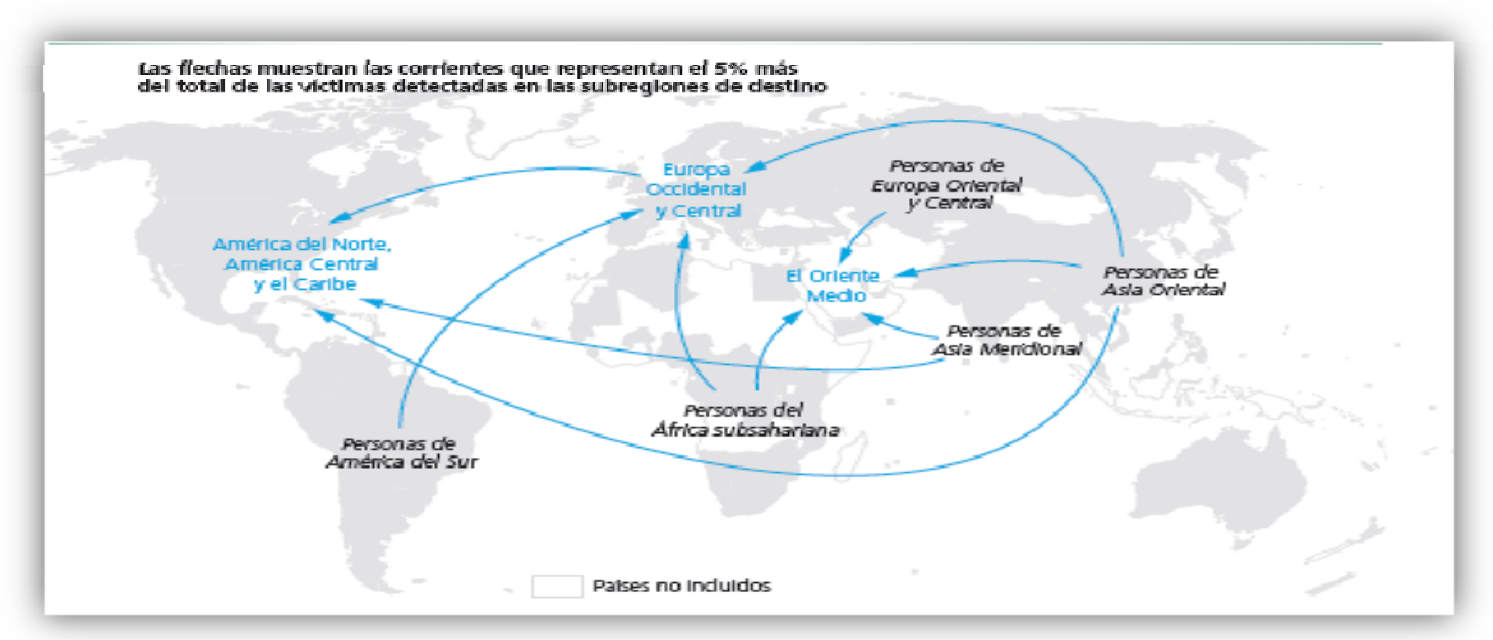

Fuente: UNODC.

\footnotetext{
${ }^{66}$ http://www.unodc.org/documents/human-trafficking/2014/GLOTIP 2014 full_report.pdf
} 
En este sentido, los grandes traficantes de personas abarcan diferentes regiones, controlando el tránsito de personas desde el continente africano al continente europeo, al tiempo que controlan un gran número de víctimas, $\mathrm{y}$, por consiguiente, tanto sus inversiones como sus ganancias son elevadas. Del mismo modo, la actividad delictiva a mayor nivel, es una actividad duradera en el tiempo.

En otro orden de cosas, en los años recientes el crimen organizado trasnacional ha actuado también en la región perpetrando otro tipo de delitos, como el tráfico de armas. El mercado mundial de armas de fuego y municiones asienta su producción en fábricas perfectamente legales y con las consiguientes licencias, mientras que las armas fabricadas de forma artesanal representan una proporción insignificante. En este sentido, en la contabilidad de la distribución mundial de las armas de fuego, muestra que, existían 875 millones de armas de fuego en el mundo a partir del año 2007 , de las cuales, un $74 \%$ se encontraba en manos civiles, un $23 \%$ en manos militares y, el 3\% restante, se encontraba en manos de los servicios encargados de hacer cumplir la ley ${ }^{67}$.

A este respecto, las operaciones de exportación e importación de armas de fuego realizadas bajo la regulación vigente, se denominan como operaciones autorizadas, mientras que, aquéllas transferencias e intercambio de armamento que no hayan sido autorizados, se consideran ilícitas ${ }^{68}$. Solo en el año 2013, la ONU registró la exportación de 1.808.904 armas de fuego en todo el mundo ${ }^{69}$.

En este sentido, los antecedentes en la región ponen de manifiesto que, debido a los importantes y cruentos conflictos civiles a lo largo de las últimas décadas han dado como resultado un intenso cambio social, que se reproduce en grandes poblaciones desplazadas y fronteras borrosas y dudosas. Más de 35 grupos armados han operado en la región, en diferentes países como Costa de Marfil, Gambia, Guinea, Guinea-Bissau, Liberia, Malí, Níger, Nigeria, Senegal y Sierra Leona. Una parte importante de estos grupos se han desmovilizado con la consecuente proliferación de armas de fuego en circulación ${ }^{70}$. A este respecto, desde la Guerra Fría, África ha sido un continente que ha estado acumulando todo tipo de armamento en grandes cantidades ${ }^{71}$, por lo que la oferta existente es suficiente para

\footnotetext{
67 Small Arms Survey 2015, en http://www.smallarmssurvey.org/fileadmin/docs/A-Yearbook/2015/sp/SmallArms-Survey-2015-About-2-Cover-sheet-SP.pdf

${ }^{68}$ Conforme al Glosario de términos, definiciones y abreviaturas de la Unidad de Coordinación de las Naciones Unidas de Acción contra las Armas Ligeras, (Nueva York: Naciones Unidas CASA, 2014, ISAC 01,20: 2014 (E) V1.1).

${ }^{69}$ UNODC Study on Firearms 2015. A study on the transnational nature of and routes and modus operandi used in trafficking in firearms, p. 21, en https://www.unodc.org/documents/firearms-protocol/UNODC_Study on_Firearms WEB.pdf

${ }^{70}$ Small Arms Survey, "Armed and aimless: Armed groups, guns and human security in the ECOWAS region". Ginebra, SAS, 2005.

${ }^{71}$ La importación de armas en el continente africano creció un 45\% entre el período 2005-2009 y 2010-2014. Argelia es el mayor importador de armas en el continente con el 30\% de todas las compradas en África, seguido por Marruecos con el 26\%, y en tercer lugar Sudán con el 6\%. Las importaciones de armamento de Argelia en el período 2010-2014 crecieron un 3\% frente al lustro anterior (2005-2009), mientras que las importaciones de Marruecos se multiplicaron por once. En 2014 una de las adquisiciones más importantes de Argelia fueron un portahelicópteros de Italia, un lote de 48 sistemas de defensa antiaérea de Rusia y unos 50 cañones autopropulsados de China, mientras que Marruecos recibió una fragata en ese mismo año de Francia, principal suministrador de Rabat (18\% de sus ventas de armamento son para el país magrebí). El documento establece cierta rivalidad armamentística entre los dos países magrebíes explicó que, contrariamente a Marruecos, Argelia tiene todavía pendiente un encargo de dos submarinos y 42 helicópteros de Rusia, y 926 vehículos blindados de transporte de tropas, en este caso de Alemania. Asimismo, atribuye las compras argelinas al 'conflicto con grupos rebeldes', en alusión a los grupos de inspiración yihadista, pero no especula sobre Marruecos, que concentra sus esfuerzos militares (humanos y armamentísticos) en el territorio del Sáhara Occidental. Informe SIPRI 2014, en http://www.sipri.org/yearbook/2014/files/sipri-yearbook-2014-resumen-en-espanol
} 
satisfacer a la demanda local ${ }^{72}$. Cabe destacar que en la región hay diversos países productores de armas: Marruecos, Argelia, Egipto o la República de Sudáfrica.

La mayoría del armamento presente en el continente africano, procede de depósitos oficiales que fueron usados en los números conflictos intra-estado ${ }^{73} \mathrm{y}$ regionales, que asolaron el continente a finales del siglo XX. En este sentido, el armamento sobrante de la guerra en Chad se trasladó al vecino Darfur; en el mismo orden de cosas, tras los conflictos de Sierra Leona, Liberia o Costa de Marfil, se ha multiplicado de forma intensa el comercio interregional, buena parte del cual lo han venido realizando las redes de crimen organizado asentadas en países como Mali o Mauritania que han sido la principal fuente de suministro de armamento de los grupos yihadistas ${ }^{74}$.

Otro es ejemplo es Libia. Desde la revolución armada que puso fin al gobierno del Coronel Gadafi en 2011, la seguridad en la frontera libia, especialmente en la zona sur, es prácticamente inexistente; y se ha convertido en una grave amenaza para toda la región. Los arsenales de armamento del antiguo régimen estaban fuera de control, y el tráfico de armas se incrementó de forma alarmante hacia los países limítrofes ${ }^{75}$.

El comercio ilícito de armas, un negocio altamente lucrativo, se realiza por vía terrestre, donde tienen un papel protagonista los soldados desmovilizados ${ }^{76}$, procedentes de los principales conflictos extinguidos, y que se aprovechan de las relaciones étnicas y tribales inter-fronterizas. En este sentido los grupos nómadas del Sahel controlan los movimientos a través de su territorio y aunque no son propietarios de las mercancías, se benefician cobrando una tarifa a sus dueños por sus servicios ${ }^{77}$. Así, el conflicto en Libia, por un lado, ha venido a modificar los movimientos de armas por la zona, puesto que el armamento que el régimen de Gadafi poseía (no existen cifras exactas) ha ido desapareciendo y difuminándose. Un ejemplo de ello son los 22.000 sistemas antiaéreos portátiles manpads ${ }^{78}$, de los cuales se habría perdido el rastro de unos 17.000 después de la revolución. Del mismo modo, otros países como Costa de Marfil, han sido sometidos a embargo de armas por la ONU, puesto que se registraban cotas muy elevadas de este comercio ilícito. En definitiva, puede entenderse que

\footnotetext{
${ }^{72}$ Fuente Cobo, Ignacio: "La amenaza híbrida: Yihadismo y crimen organizado en el Sahel". IEEE, No 57/2014. (3 de diciembre de 2014), p. 12.

${ }^{73}$ De acuerdo con el Conflict Barometer 2014. Heidelberger Institut für Internationale Konfliktforschung (HIIK). 2014. Este barómetro fija en el año 2014, en 25 las guerras limitadas y en 21 las guerras abiertas en todo el mundo. En África Sub-Sahariana identifica conflictos en: República Centroafricana, República Democrática del Congo, Sudán del Sur, Uganda (LRA), República Democrática del Congo (Bantu-batwa/Katanga), República Democrática del Congo (violencia entre milicias), República Democrática del Congo (milicias de Ituri), República Democrática del Congo (Kata Katanga/Katanga), República Democrática del Congo (Mayi-Mayi), Kenya (violencia interétnica), Mali (grupos islamistas), Sudán del Sur (violencia interétnica), República Centroafricana (Anti-Balaka-ex Seleka), República Democrática del Congo, Uganda (ADF), Nigeria (Boko Haram), Nigeria (agricultores y pastores), Somalia (grupos islamistas), Sur de Sudán (SPLM/A-en la oposición), Sudán (Darfur), Sudán (violencia interétnica), Sudán (SPLM/A-Norte/Sur de Kordofan, el Nilo Azul).

${ }^{74}$ Para más información ver: Mesa, Beatriz (2013): La Falsa Yihad, El negocio del narcotráfico en El Sahel. Cádiz, Ediciones Dalya.

${ }^{75}$ Díez Alcalde, Jesús: "II Conferencia Regional Sobre Seguridad de Fronteras: Por la Estabilidad del Magreb y Sahel". IEEE 64/2013. (27 de noviembre de 2013), en http://www.ieee.es/Galerias/fichero/docs_analisis/2013/DIEEEA642013_ConferenciaSeguridadFronteras.JDA.p df.

${ }^{76}$ AU Strategy for the Sahel, en http://www.iag-agi.org/IMG/pdf/strategy-of-au-for-sahel.pdf.

${ }^{77}$ Fuente Cobo, Ignacio. "La amenaza híbrida: Yihadismo y crimen organizado en el Sahel". IEEE. № 57/2014. (3 de diciembre de 2014), p. 12.

${ }^{78}$ Man-portable air defence system: Sistemas antiaéreos portátiles extraordinariamente eficaces por su corto alcance y guiado infrarrojo contra aeronaves a bajo vuelo, y extraordinariamente peligrosos para los aviones civiles en maniobras de aproximación o despegue de un aeropuerto. Fuente Cobo, I. La amenaza hibrida:

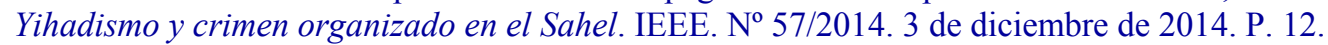


en la región, armas traficadas desde Libia a través de Níger y Argelia habrían servido para iniciar la revuelta tuareg por el Azawad maliense que tuvo lugar en el año 2012. Del mismo modo, los grupos terroristas han adquirido, con los réditos del crimen organizado, se han logrado hacer acopio de arsenales perdidos de otras guerras y conflictos existentes en el continente ${ }^{79}$.

En otro orden de cosas, es necesario poner de manifiesto que la región registra otro tipo de actividad delictiva. A las actividades de tráfico de drogas, personas y armas, se le unen, las actividades que realizan grupos como los tuareg, como son el contrabando de tabaco, falsificaciones, dinero, metales preciosos así como mercancías no declaradas, como por ejemplo diversos tipos de medicamentos ${ }^{80}$. La repercusión de este tipo de contrabando es principalmente fiscal, en la medida en que afecta a las tasas e impuestos, si bien entrañan un riesgo desde el punto de vista de la seguridad, en la medida en la que pueden afectar principalmente al bienestar de los usuarios locales. Este contrabando se realiza a gran escala, aprovechando tanto los numerosos contenedores, como la permeabilidad de las fronteras en la zona. Así, cuando existen focos donde se realiza un control más exhaustivo de mercancías traficadas, se produce una diversificación de los intercambios mediante diversos flujos: por un lado peatonales (menudeo a través de Ceuta, Melilla y La Línea), por otro náuticos (puertos deportivos del Mediterráneo) y por último, fronterizos (automóviles) para concentrase y redistribuirse posteriormente hacia el resto de Europa ${ }^{81}$.

Otro aspecto al que debemos hacer referencia, es el lavado de dinero, que consiste en lograr que los fondos o activos procedentes de actividades ilícitas, aparezcan como fruto de actividades lícitas, y logren circular por el circuito legal del sistema financiero. En este sentido, los flujos ilícitos incluyen las transferencias de fondos ganados mediante la corrupción, sobornos, evasión fiscal, delincuencia y contrabando y otros ilícitos, al tiempo que incluye los fondos sacados ilegalmente del país aunque su origen sea legal, incluidos las fortunas amasadas gracias a la captura de rentas desde el poder. A este respecto, es importante subrayar lo paradójico e inexplicable de que se localicen importantes cantidades de euros en países como Mauritania, Mali o Ghana. A este respecto, el Banco Africano de Desarrollo (AfDB), así como la Global Financial Integrity ${ }^{82}$, consideran que los países de Oriente Medio y el norte de África lideran los movimientos de capitales ilícitos de los países en desarrollo, con un crecimiento anual del $26,3 \%^{83}$. El siguiente mapa muestra de un vistazo el elevado número y tramas financieras ilícitas existentes en la región (véase Figura 6)

\footnotetext{
${ }^{79}$ Fuente Cobo, Ignacio: "La amenaza híbrida: Yihadismo y crimen organizado en el Sahel". IEEE. No 57/2014. (3 de diciembre de 2014), p. 12.

${ }^{80}$ UNODC ha identificado el contrabando de medicinas en África Occidental como otra actividad de las redes criminales. $2013^{\mathrm{a}}$, pp. 39-42.

${ }^{81}$ Arteaga, Félix: "España mirando al Sur: del Mediterráneo al Sahel". Informe Elcano. (Noviembre 2014), p. 69-71, en:

http:/www.realinstitutoelcano.org/wps/wcm/connect/349a5b80467ff303b17db7bdae0ed545/InformeElcano18 Espana mirando al_sur_mediterraneo sahel.pdf?MOD=AJPERES\&CACHEID=349a5b80467ff303b17db7bdae $\underline{0 \text { ed545 }}$

${ }^{82}$ Global Financial Integrity. Informe sobre Flujos Financieros Ilícitos de los países en desarrollo 2012.

${ }^{83} \mathrm{http}: / /$ www.gfintegrity.org/storage/gfip/documents/noneconomist $\% 20$ recent $\% 20$ capital $\% 20 f l i g h t ~ \% 20$ finalesre vised.pdf
} 
Figura 6

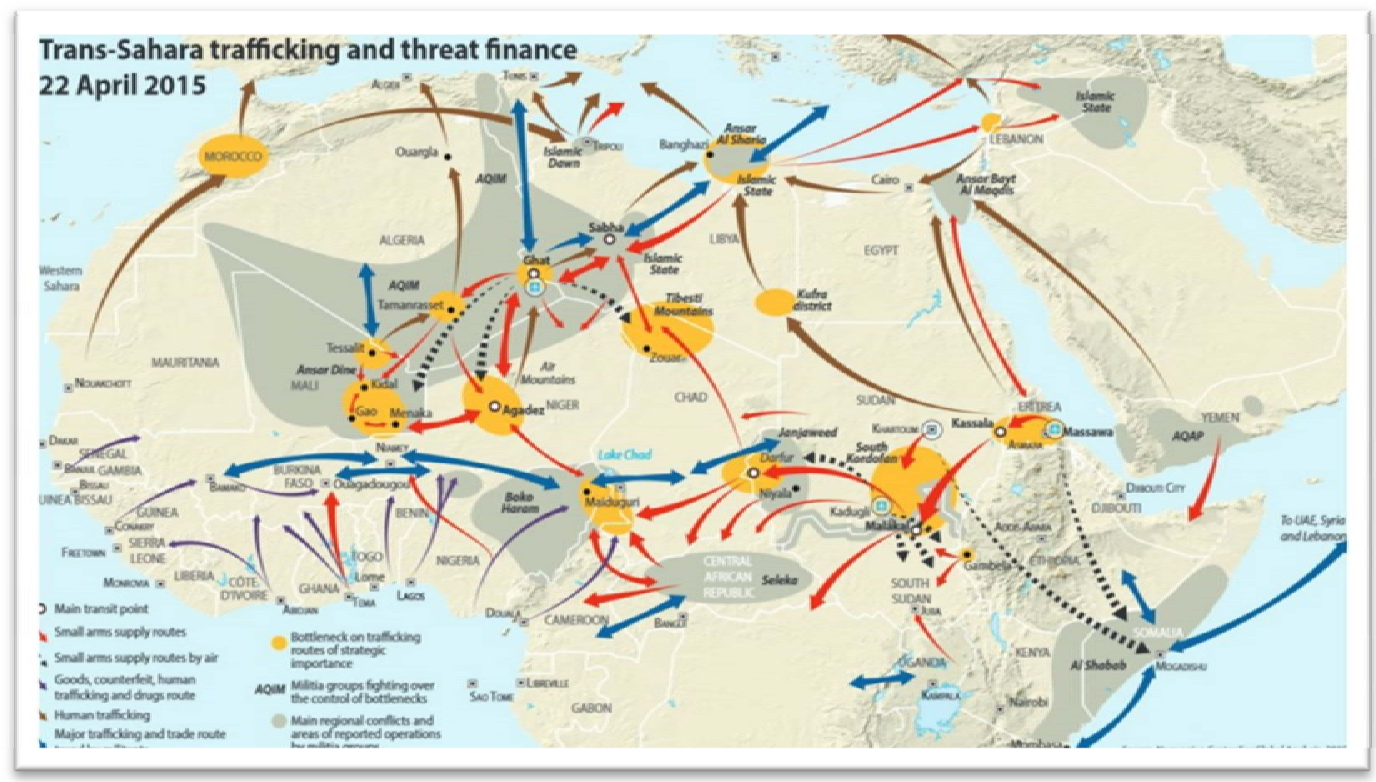

Fuente: Norwegian Center for Global Analysis, 2015.

De este modo, países como Argelia ${ }^{84}$, Libia, Nigeria y, en menor medida Egipto, figuran como los países cuyo saldo neto de transferencias les permite ocupar las primeras posiciones del tráfico ilícito en la zona, mientras que Sudán, Túnez, Marruecos ${ }^{85}$ y Costa de Marfil ocupan las últimas posiciones. Por lo tanto, de todos los países, los del norte de África serían los que más se han significado por este flujo: el $83 \%$ de todos los fondos ilícitos transferidos (unos 30 billones anuales de dólares). Se constata que la zona es un auténtico polvorín y que se requieren verdaderas estrategias y esfuerzos para lograr que esta región deje de ser un campo de cultivo y un escenario propicio tanto para el crimen organizado como para el terrorismo.

En definitiva, en años recientes, el crimen organizado transnacional en África Occidental, o el crimen perpetrado por africanos occidentales en otras partes del mundo, se ha convertido en una amenaza a nivel global. En este sentido podrían encuadrarse los grupos criminales que se dedican a los delitos de estafa. Así, y a pesar de que el crimen organizado proveniente de esta región puede considerarse menos violento que por el ejemplo la mafiya (crimen organizado ruso), o la yakuza japonesa ${ }^{86}$, su escala y rango llaman poderosamente la atención, puesto que han desarrollado una presencia allí donde existe cualquier oportunidad para el crimen.

\footnotetext{
84 "Algeria, corruption and Islamic militancy". London School of Economics and Political Science. (20 de noviembre de 2013), en http://blog.lse.ac.uk/africaatlse/2013/11/20algeria-corruption-and-islamic-militance

${ }^{85}$ Business Corruption in Morocco. NORAD. Austrian Development Agency. 2015 Business Anticorruption Portal, en http://www.business-anti-corruption.com/country-profiles/middle-east-Morocco

${ }^{86}$ Herrero, Rubén, Barras, Raquel: "Globalización y crimen organizado. Mecanismos de lucha contra el crimen transnacional: la inteligencia". Inteligencia y Seguridad: Revista de análisis y prospectiva, $\mathrm{n}^{\mathrm{o}} 6$ (2009), p. 99122.
} 


\section{Contexto Internacional: Mecanismos de lucha}

Como ya se ha puesto de manifiesto en la primera parte del artículo, la situación de debilidad y la inexistencia de las principales herramientas para hacer frente al crimen organizado en este flanco sur profundo que supone la región del Magreb y parte del Sahel, ponen de manifiesto la insuficiente cooperación policial y judicial en los países de la zona así como con los países europeos a los que le supone una amenaza a su seguridad de primer nivel.

La Convención de las Naciones Unidas contra el Crimen Organizado Transnacional ${ }^{87}$ (UNTOC, por sus siglas en inglés) no contiene una definición precisa del término "crimen transnacional organizado" ni incluye una lista de los tipos de delitos que podrían constituirlo. Esta ausencia de definición fue pensada para permitir una aplicación más amplia de la UNTOC a los nuevos tipos de delito que emergen constantemente, a medida que las condiciones locales, regionales y globales se modifican en el tiempo. Así, la Convención posee la definición de lo que sí es un 'grupo criminal organizado'. En particular, en su artículo 2(a) se define como 'grupo delictivo organizado' a: "un grupo estructurado de tres o más personas que exista durante cierto tiempo y que actúe concertadamente con el propósito de cometer uno o más delitos graves o delitos tipificados con arreglo a la presente Convención con miras a obtener, directa o indirectamente, un beneficio económico u otro beneficio de orden material". De este modo, el término genérico se refiere tanto a los delitos cometidos en más de un Estado como también aquéllos que tienen lugar en un único Estado por llevadas a cabo por grupos que operan en más de un país. Se pone de manifiesto, por tanto, la complejidad añadida del problema al ser global, y, como se plantea con acierto en la UNTOC, "Si la delincuencia atraviesa las fronteras, lo mismo ha de hacer la acción de la ley. Si el imperio de la ley se ve socavado no sólo en un país, sino en muchos países, quienes lo defienden no se pueden limitar a emplear únicamente medios y arbitrios nacionales" ${ }^{\prime 8}$.

En primer lugar es necesario subrayar que estos países son, en muchos casos, estados fallidos con un vacío de poder alarmante, al tiempo que no disponen de los recursos necesarios (económicos, humanos, técnicos o legales), así como de las capacitaciones necesarias (ejércitos, inteligencia, etc.) para hacer frente a este tipo de amenazas. En el mismo sentido, resulta indispensable que los países de la zona se comprometan a institucionalizar de alguna forma no solo la inteligencia, como pieza clave en la lucha contra el crimen organizado $^{89}$, sino también los mecanismos de cooperación existentes entre las instituciones y las fuerzas y cuerpos de seguridad de los diferentes estados implicados. Sin una cooperación verdadera, los esfuerzos que se realicen, no serán suficientemente eficaces a la hora de abordar una problemática de este nivel.

A continuación se van a repasar los mecanismos existentes en materia de lucha contra el crimen organizado, por un lado a nivel internacional, por otro las iniciativas puestas en marcha a nivel regional, y, por último, la labor que se realiza desde España, una institución como el CITCO, en particular en su enfoque a combatir el crimen organizado en el Magreb y el Sahel.

\footnotetext{
${ }^{87}$ Convención de las Naciones Unidas contra la Delincuencia Organizada Trasnacional y sus Protocolos. Art. 2 a) Nueva York, 2004, en https://www.unodc.org/documents/treaties/UNTOC/Publications/TOC\%20Convention/TOCebook-s.pdf ${ }_{88}$ Convención de las Naciones Unidas contra la Delincuencia Organizada Trasnacional y sus Protocolos. Prefacio. Nueva York, 2004. Disponible en: https://www.unodc.org/documents/treaties/UNTOC/Publications/TOC\%20Convention/TOCebook-s.pdf

${ }^{89}$ Herrero, Rubén, Barras, Raquel: "Globalización y crimen organizado. Mecanismos de lucha contra el crimen transnacional: la inteligencia". Inteligencia y Seguridad: Revista de análisis y prospectiva, n $^{\circ} 6$ (2009), p. 99122.
} 


\subsection{Mecanismos de lucha a nivel global ${ }^{90}$}

En el año 2014, tuvo lugar la séptima reunión de la Conferencia de las Partes de la Convención de las Naciones Unidas contra la Delincuencia Organizada Transnacional. Inicialmente, el año 1994 marca un antes y un después en lo que a la concienciación por parte de la comunidad internacional, respecto al crimen organizado se refiere, puesto que tiene lugar, en la ciudad de Nápoles, la primera Conferencia Mundial sobre Delincuencia Organizada Transnacional. Esta conferencia, bajo los auspicios de la ONU, desarrolló una nueva corriente de visibilidad sobre esta materia, vertebrando un entorno legal propicio para luchar contra la delincuencia. La citada Convención y los tres protocolos adicionales, se abrieron a la firma en Palermo, Italia en el año 2000, (por lo que es conocida como la Convención de Palermo) y en el momento fue aclamada como un paso trascendental en la lucha mundial contra el crimen organizado. En este sentido, la Convención entró en vigor hace diez años, en 2003, una vez que 40 Estados habían pasado a ser parte de sus disposiciones, y, posteriormente, en diciembre de 2013, formaban parte de dicha Convención 179 Estados. Las primeras directrices abordadas en la Convención de Palermo, constituyen el marco de acción para el Programa Global contra el crimen organizado de la Oficina de Naciones Unidas contra la Droga y el Delito (UNODC) ${ }^{91}$. Adicionalmente, la UNODC contempla delitos de muy variada índole, en lo que a actividades del crimen organizado se refiere: corrupción, prevención del crimen, justicia penal, tráfico de drogas, prevención y tratamiento, armas de fuego, medicamentos fraudulentos, trata de seres humanos, lavado de dinero, piratería y crímenes marítimos, terrorismo, delitos contra el medio ambiente y delitos forestales ${ }^{92}$.

En este sentido, a nivel internacional se han ido poniendo en marcha diversos $\operatorname{Tratados}^{93}$ conforme a los delitos específicos, además de la citada Convención contra la Delincuencia Organizada Transnacional: la Convención contra la Corrupción ${ }^{94}$, Convención Única sobre estupefacientes $^{95}$, Convenio sobre Sustancias Psicotrópicas ${ }^{96}$, Convención contra el Tráfíco Ilícito de Estupefacientes y Sustancias Psicotrópicas ${ }^{97}$ así como otros Convenios antiterroristas. Adicionalmente se han puesto en marcha numerosas campañas ${ }^{98}$, comisiones $^{99}$,

\footnotetext{
${ }^{90}$ Ver Barras, Raquel: "España y el crimen organizado: ¿Asignatura pendiente de la Estrategia Española de Seguridad?" V Jornadas de Estudios de Seguridad. IUGM. (Mayo, 2013), en: http://iugm.es/uploads/tx iugm/ACTAS V JORNADAS DE EST DE SEG.pdf

${ }_{91}$ Incluyendo cinco programas adicionales, centrados en ámbitos específicos: trata de personas, lavado de activos, corrupción, terrorismo y asistencia legal.

${ }^{92}$ UNODC. https://www.unodc.org/unodc/en/piracy/index.html?ref=menuside

93 Estos acuerdos, proporcionan el fundamento jurídico de la acción contra la delincuencia organizada transnacional, y reflejan el acuerdo de la comunidad internacional sobre la tesis de que para abordar este problema de forma eficaz, es esencial la colaboración de todos los estados afectados o involucrados. UNODC.

94 Resolución 55/61 de diciembre de 2000, de la Asamblea General. Reconoció la necesidad de crear un instrumento jurídico internacional eficaz contra la corrupción, independiente de Convención de las Naciones Unidas contra la Delincuencia Organizada Transnacional (resolución 55 /25, anexo I). En este sentido, el Convenio (aprobado por el Comité Ad Hoc) fue adoptada por la Asamblea General en su resolución 58/4 de 31 de octubre de 2003. La Asamblea General, en su resolución 57/169, de 18 de diciembre de 2002, aceptó el ofrecimiento del Gobierno de México para ser sede de una conferencia política de alto nivel en Mérida para la firma de este documento. Así, la Convención de las Naciones Unidas contra la Corrupción Entró en vigor el 14 de diciembre de 2005. Actualmente hay 140 Estados signatarios y 170 forman parte.

${ }^{95}$ Convención Única sobre Estupefacientes de 1961. Enmendada por el Protocolo que modifica la Convención Única sobre Estupefacientes de 1961. Nueva York, 8 de agosto 1975.

${ }^{96}$ Convenio Sobre Sustancias psicotrópicas. Viena, 21 de febrero 1971.

${ }^{97}$ Convención contra el Tráfico Ilícito de Estupefacientes y Psicotrópicas Naciones Unidas Sustancias, 1988. Esta Convención establece medidas integrales contra el tráfico de drogas, lavado de dinero y contra Disposiciones (incluyendo el desvío de precursores químicos). Se prevé la cooperación internacional a través de, por ejemplo, la extradición de narcotraficantes, la entrega vigilada y remisión de las actuaciones.

${ }^{98}$ Día Mundial de las Drogas, el 26 de junio; Día contra la Corrupción el 9 de diciembre de cada año.
} 
congresos $^{100}$ e informes ${ }^{101}$, que ofrecen amplia información sobre la situación, tendencias y análisis actualizado de los mercados del crimen. Del mismo modo, cabe destacar las diversas herramientas legales ${ }^{102}$ que se han puesto en marcha en el seno de la organización.

Cabe destacar que en materia de drogas, la ONU cuenta con la ONUDD que viene desarrollando de forma paulatina nuevas herramientas de cooperación internacional para la lucha contra el tráfico de drogas y estupefacientes. En particular, elabora manuales, un directorio en línea de autoridades nacionales competentes, una herramienta de redacción de solicitudes de asistencia judicial recíproca, una base de datos jurídica y mejor jurisprudencia práctica. En este sentido la ONUDD trabaja con los Estados partes en la Convención contra la Delincuencia Organizada tanto dentro de sus propias fronteras nacionales y entre las regiones.

Del mismo modo, la OTAN introduce en el año 1999, en su revisión del Concepto Estratégico, la delincuencia organizada como uno de los retos para la seguridad en los estados miembros. Del mismo modo, en el año 2004, en el Informe presentado por las Naciones Unidas 'A more secure World: Our shared responsibility' ${ }^{103}$, se señalaba a la delincuencia organizada transnacional como una de las seis mayores amenazas a la estabilidad mundial. Actualmente el crimen organizado se ha incrementado exponencialmente y se ha convertido en un problema de primer orden para la seguridad de todos los países tal y como ha quedado reflejado a lo largo del artículo. Las operaciones de la OTAN en el Mediterráneo podrían ser también incluidas como un elemento potenciador de la eficacia y mejora en actividades de recogida, recopilación e intercambio de información ${ }^{104}$. Asimismo, con el fin de establecer un mayor control en la región, podría implementarse desde los países miembros del flanco sur de la OTAN: España, Francia, Italia, Grecia y Turquía y en parte Portugal, una fusión entre los mecanismos de que se disponen para hacer frente por un lado al terrorismo y, por otro, al crimen organizado, con el fin de ser más flexibles. Esta propuesta incluye el establecimiento de una serie de medidas regionales tanto en el Sahel como en el Magreb. Puede ser una oportunidad para hacer frente a esta amenaza, que se creen nuevos mecanismos dirigidos por los países del flanco sur de la OTAN, que incluyan un enfoque estratégico en lo que a la gestión de las fronteras y la lucha contra el tráfico ilícito y la delincuencia organizada transnacional se refiere ${ }^{105}$.

\footnotetext{
99 Se crean las siguientes Comisiones: de Estupefacientes; de Prevención del Delito y Justicia Penal; de Gobernanza y Finanzas y la Secretaría a los Órganos de Gobierno. Asimismo el Consejo Económico y Social creó una mesa redonda dedicada a la importancia de la fiscalización de drogas, prevención del delito y justicia penal en el contexto de la agenda de desarrollo post- 2015.

${ }^{100}$ El próximo congreso sobre la materia está previsto que se celebre en Qatar en el año 2015. Anteriormente, y con una periodicidad de 5 años se han venido celebrando Congresos sobre esta materia, desde que se iniciara en el año 1955, en Ginebra.

${ }^{101}$ Informes de carácter anual: Informe Mundial sobre las Drogas, Informe mundial sobre la trata de personas; evaluaciones de la amenaza del crimen organizado transnacional; estadísticas; estudios y publicaciones; boletín de Estupefacientes contiene artículos técnicos y científicos sobre temas relacionados con los estupefacientes; Foro sobre el Delito y la Sociedad; Encuestas; y diversas encuestas sobre: Monitoreo de Cultivos Ilícitos y tendencia de la delincuencia (CTS), entre otras.

${ }^{102}$ Herramientas como la Biblioteca Legal; bases de datos sobre tráfico de seres humanos; directorios de autoridades nacionales competentes; Asistencia Legal Mutua; redes de Cooperación Internacional.

${ }^{103}$ Informe elaborado por el Grupo de alto nivel sobre las amenazas, los desafíos y el cambio de la ONU: ' $A$ more secure World: Our shared responsibility', en

https://www.un.org/en/peacebuilding/pdf/historical/hlp_more_secure_world.pdf

${ }_{104} \mathrm{http} / /$ www.nato-pa.int/default.asp?SHORTCUT $=368$

105 In terms of strategic focus it seems particularly important to further develop: 1) Preventing and countering radicalization; 2) Create appropriate conditions for Youth; 3) Migration and mobility; 4) Border management and fight against illicit trafficking and transnational organized crime. Council conclusions on the Sahel Regional Action Plan 2015-2020. Bruselas, 20 abril 2015.7823/15. Annex, p. 7.
} 
En lo que a la corrupción se refiere, en particular la corrupción perpetrada a nivel institucional $^{106}$ es importante señalar que esta corrupción es una pieza fundamental a la hora de entender el éxito de los sindicatos del crimen. De este modo, en Marruecos, Argelia o Libia, ocupan respectivamente los puestos 80, 100 y 166 del ranking (fijado en175) ${ }^{107}$. De este modo, la existencia de mecanismos expresamente diseñados de lucha contra la corrupción, como la Anti-Bribery Convention de la $\mathrm{OCDE}^{108}$, que tanto su eficacia así como su repercusión es nula. En este sentido, es importante señalar los índices alarmantes que existen en la mayoría de los países inestables del Sahel respecto a lo que se entiende por rule of law. El siguiente gráfico muestra de manera clara como estos países se encuentran a la cola en lo que al respeto y al cumplimiento de la ley se refiere, de todos los países del África subsahariana (véase Figura 7).

Figura 7

\section{So ordered}

Rule-of-law index in sub-Saharan Africa, $1=b e s t$

Botswana

Ghana

South Africa

Senegal

Malawi

Tanzania

Zambia

Ivory Coast

Burkina Faso

Madagascar

Liberia

Kenya

Sierra Leone

Ethiopia

Uganda

Nigeria

Cameroon

Zimbabwe

Source: World Justice Project

$\begin{array}{lllll}0.3 & 0.4 & 0.5 & 0.6 & 0.7\end{array}$

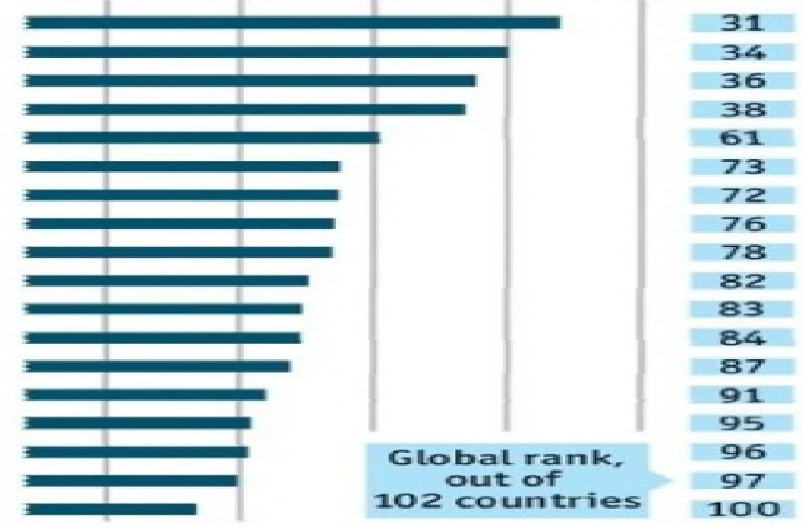

Economist.com

Fuente: Economist.com.

El resto de países del Magreb, y que no aparecen en este gráfico, presentan unos déficits alarmantes en lo que a lucha contra la corrupción se refiere. El caso de Libia, sumido en la actual situación, puede no ser significativo, pero en el caso de Marruecos, y a pesar de los continuos alegatos de lucha contra la corrupción, es necesario denunciar una corrupción inherente a las instituciones, uno de los principales problemas, donde el crimen se perpetúa.

\footnotetext{
${ }^{106}$ Global Corruption Barometer 2013. Transparencia Internacional, en http://issuu.com/transparencyinternational/docs/2013 globalcorruptionbarometer en/1?e=2496456/3903358

${ }_{107}$ Corruption Perceptions Index 2014, en: http://www.transparency.org/cpi2014/results.

108 Se trata de una convención de la OCDE destinada a la reducción de corrupción en los países en desarrollo mediante el fomento de las sanciones contra el soborno en las transacciones comerciales internacionales llevadas a cabo por empresas con sede en los países miembros de la Convención. Su objetivo es crear una auténtica igualdad en el entorno de los negocios internacionales. Convention on combating bribery of foreign public officials in international business transactions and related documents. en: http://www.oecd.org/daf/antibribery/ConvCombatBribery ENG.pdf
} 
Las iniciativas puestas en marcha en el seno de las instituciones internacionales no arrojan un saldo positivo, en tanto en cuanto, como se ha visto en el artículo, en la mayoría de estos países el crimen organizado está plenamente integrado en la sociedad y en las instituciones y constituye, en ocasiones, una forma de vida. En este sentido las medidas emprendidas deben ser comprehensivas, y que más allá de las acciones específicas de desarticulación de grupos criminales o de grupos terroristas, lo que deben conseguir es, con la implicación de los países afectados, un nivel socioeconómico aceptable para que dedicarse al crimen organizado no sea un negocio rentable, y sí un auténtico problema para quienes lo realizan.

\subsection{Mecanismos de lucha a nivel regional}

En lo relativo al Magreb y parte del Sahel, es importante destacar que toda actuación de la comunidad internacional que mejore su situación sociopolítica disminuirá la proyección de las amenazas hacia Europa.

En primer lugar, es importante subrayar el papel destacado que tienen las iniciativas puestas en marcha por Estados Unidos en la zona, principalmente centradas en la lucha contra el terrorismo, aunque como vimos antes, hay una estrategia contra el crimen organizado transnacional que observa además el nexo crimen-terrorismo. Además, EEUU ha mantenido todo una serie de iniciativas y estrategias para la zona que fueron reforzadas una vez que se creó el AFRICOM, el mando norteamericano para Africa ${ }^{109}$. Con otra serie de iniciativas que quedaron bajo el mando del AFRICOM, el gran problema fue siempre la poca cooperación conseguida entre los estados del Magreb, y de estos con el Sahel.

La estrategia de seguridad nacional de EEUU de 2002 ya hablaba de estados fallidos como amenaza a la seguridad nacional, ya que permitía el refugio de grupos terroristas: "America is now threatened less by conquering states than [...] by failing ones" ${ }^{110}$. El director de la CIA, George Tenet establecía en 2003 ante el Comité de Inteligencia del Senado de EEUU una clara aproximación a este concepto: "the world's vast stretches of ungoverned areas where extremist movements find shelter and can win the breathing space to grow" ${ }^{111}$. Así, la estrategia militar de EEUU en 2004 los definiría, incluyendo ya la alianza entre grupos extremistas y crimen organizado: "There exists an "arc of instability" stretching from the Western Hemisphere, through Africa and the Middle East and extending to Asia. There are areas in this arc that serve as breeding grounds for threats to our interests. Within these areas rogue states provide sanctuary to terrorists, protecting them from surveillance and attack. Other adversaries take advantage of ungoverned space and under-governed territories from which they prepare plans, train forces and launch attacks. These ungoverned areas often coincide with locations of illicit activities; such coincidence creates opportunities for hostile coalitions of criminal elements and ideological extremists"112. El Quadrennial Defense

\footnotetext{
109 Para una explicación de estas iniciativas (por ejemplo de la TSCTI, Trans-Saharan Counter-Terrorism Initiative, que incluía entrenamiento y equipamiento de seguridad a Mauritania, Mali, Niger and Chad, y se dirigía a 11 estados en el área Sahara-Sahel como Argelia, Mauritania, Senegal, Mali, Burkina-Faso, Nigeria, Niger, Chad, Libia, Marruecos y Túnez) y la creación del AFRICOM véase García Cantalapiedra, David. "La creación del AFRICOM y los objetivos de la política de EEUU hacia África: gobernanza, contraterrorismo, contrainsurgencia y seguridad energética". ARI $N^{o} 53 / 2007$, (10 de mayo de 2007), en http://www.realinstitutoelcano.org/wps/wcm/connect/d72763804f01876dbd0cfd3170baead1/ARI53-

2007 Garca_Cantalapiedra_AFRICOM_EEUU.pdf?MOD=AJPERES\&CACHEID=d72763804f01876dbd0cfd3 170 baead 1

${ }^{110}$ The National Security Strategy of the United States. The White House. 2002. p.1.

${ }^{111}$ US Senate. Select Committee on Intelligence, testimony of Director George J. Tenet, DCI's Worldwide Threat Briefing, The Worldwide Threat in 2003: Evolving Dangers in a Complex World, February 11, 2003.

${ }^{112}$ CJCS: The National Military Strategy of the United States of America. A Strategy for Today; a Vision for Tomorrow. 2004. p. 15.
} 
Review de 2006 lo establecería dentro de la idea de "Long War"113. La RAND Corporation también los definía en 2007 como "ungoverned territory": "An area in which a state faces significant challenges in establishing control. Ungoverned territories can be failed or failing states, poorly controlled land or maritime borders, or areas within otherwise viable states where the central government's authority does not extend. Ungoverned territories can also extend to airspace..."

Desde 2010 la Administración Obama lanzó una iniciativa contra el crimen organizado transnacional, Transnational Organized Crime: A Growing Threat to National and International Security, teniendo en cuenta el creciente aumento de la relación entre los grupos terroristas, insurgentes y las diferentes organizaciones criminales: "Crime-Terror-Insurgency Nexus. Terrorists and insurgents increasingly are turning to TOC to generate funding and acquire logistical support to carry out their violent acts. The Department of Justice reports that 29 of the 63 organizations on its FY 2010 Consolidated Priority Organization Targets list, which includes the most significant international drug trafficking organizations (DTOs) threatening the United States, were associated with terrorist groups. Involvement in the drug trade by the Taliban and the Revolutionary Armed Forces of Colombia (FARC) is critical to the ability of these groups to fund terrorist activity. We are concerned about Hizballah's drug and criminal activities, as well as indications of links between al Qaida in the Lands of the Islamic Maghreb and the drug trade" ${ }^{115}$. Posteriormente, el Consejo de Seguridad Nacional, NSC, establecería una estrategia contra el crimen organizado transnacional con diferentes áreas prioritarias. Además, en ella encontramos una definición de lo que se considera crimen organizado transnacional: "Transnational organized crime refers to those self-perpetuating associations of individuals who operate transnationally for the purpose of obtaining power, influence, monetary and/or commercial gains, wholly or in part by illegal means, while protecting their activities through a pattern of corruption and/ or violence, or while protecting their illegal activities through a transnational organizational structure and the exploitation of transnational commerce or communication mechanisms"116.

Por otro lado, la visión europea se movió más en esta concepción, abandonando una aproximación reducida a la lucha contraterrorista, estableciendo el nexo entre desarrollo y seguridad, que como veremos en el desarrollo de las estrategias hacia el Sahel, mantendrá

\footnotetext{
${ }^{113}$ DOD. Quadrennial Defense Review Report. February 6, 2006, pp.9- 12.

${ }^{114}$ Rabasa, Angel, Boraz, Steven, Chalk, Peter, Chagrin, Kim, Karasik, Theodore W., Moroney, Jennifer D. P., O’Brien, Kevin A. \& John E. Peters: Ungoverned Territories: Understanding and Reducing Terrorism Risks. Santa Monica, CA: RAND Corporation 2007. Pág. 1. El informe dedica todo un capítulo a África Occidental (173-206), y otro al llamado corredor de África Oriental, considerando ambos áreas sin gobierno: falta de penetración del Estado en la sociedad, sin monopolio del uso de la fuerza, ausencia de control de las fronteras e interferencias externas.

115 Transnational Organized Crime: A Growing Threat to National and International Security https://www.whitehouse.gov/administration/.../transnational-crime/threat

${ }^{116}$ Strategy to Combat Transnational Organized Crime: Addressing Converging Threats to National Security. https://www.whitehouse.gov/administration/eop/nsc/transnational-crime; "There is no single structure under which transnational organized criminals operate; they vary from hierarchies to clans, networks, and cells, and may evolve to other structures. The crimes they commit also vary. Transnational organized criminals act conspiratorially in their criminal activities and possess certain characteristics which may include, but are not limited to: In at least part of their activities they commit violence or other acts which are likely to intimidate, or make actual or implicit threats to do so; They exploit differences between countries to further their objectives, enriching their organization, expanding its power, and/or avoiding detection/apprehension; They attempt to gain influence in government, politics, and commerce through corrupt as well as legitimate means; They have economic gain as their primary goal, not only from patently illegal activities but also from investment in legitimate businesses; and They attempt to insulate both their leadership and membership from detection, sanction, and/ or prosecution through their organizational structure".
} 
como núcleo central de su justificación ${ }^{117}$. Es necesario así, reconocer que en el ámbito de la Unión Europea, se está llevando a cabo un debate sobre la redefinición de la Política de Vecindad, para asegurar que se logre crear un espacio de prosperidad, estabilidad y cooperación, que ponga de relieve la importancia del Mediterráneo Sur, donde la incidencia del crimen organizado es una cuestión capital. Así, las esferas de cooperación regional en el Mediterráneo, han evolucionado desde el anterior Proceso de Barcelona a la presente Unión por el Mediterráneo y el Foro de Diálogo en el Mediterráneo Occidental $(5+5)$, donde actualmente el crimen organizado es tratado como una amenaza de primer nivel para la estabilidad de la región.

Asimismo la Unión Europea empezó en 2008 a desarrollar borradores para la realización una estrategia para el Sahel. El documento que finalmente se adoptó en marzo de 2011, ha pretendido establecer un tratamiento comprehensivo seguridad-desarrollo: "Linking human development, human rights and transnational responsibility to self-sustainable social and economic structures, the Strategy has paved the ground for large scale comprehensive regional action. Yet, the security chapter of the strategy is lagging behind, notably with regard to counter-terrorism initiatives which remain at an embryonic stage of discussion and negotiation, in a context where urgency increases ${ }^{118}$. Cabe destacar que este enfoque "clásico" de la UE, desde un punto de vista de seguridad humana básicamente ${ }^{119}$, ignoraba el creciente nexo entre el terrorismo (ya de hecho poco desarrollado en esta estrategia) con el crimen organizado, si bien estudiado y reconocido en el área, con lo que dejaba la aproximación de la UE sesgada y proclive a ser incapaz de dar una aproximación (o una solución) comprehensiva al área, tal como reclamaba. Esto incluía una cierta incomprensión sobre la compleja interdependencia de las dinámicas, centrándose además en los estados más debilitados, pero ignorando a Nigeria y Argelia ${ }^{120}$.

\footnotetext{
${ }^{117}$ Council conclusions on a European Union Strategy for Security and Development in the Sahel. 21 March 2011, p. 1 , en http://www.consilium.europa.eu/uedocs/cms_Data/docs/pressdata/EN/foraff/120075.pdf

${ }_{118}$ Hatzigeorgopoulos, M. "The EU's Strategy for the Sahel: a new turn in EU external action?" European Security Review. ISIS Europe. (Enero 2013).

119 Véase por ejemplo los documentos 2003 European Security Strategy, 2005, European Consensus on Development y 2007 Joint Africa-EU Strategy.

${ }^{120}$ IPI. Security and development in the Sahel-Sahara. IPI Meeting Notes. New York, International Peace Institute. Octubre 2013; Bello, Oladiran. "Quick fix or quicksand? Implementing the EU Sahel Strategy". Working Paper, $\mathrm{n}^{\mathrm{o}}$ 114. FRIDE. (Madrid, 2012), en http://fride.org/download/WP 114_Implementing the EU Sahel Strategy.pdf
} 
Figura 8

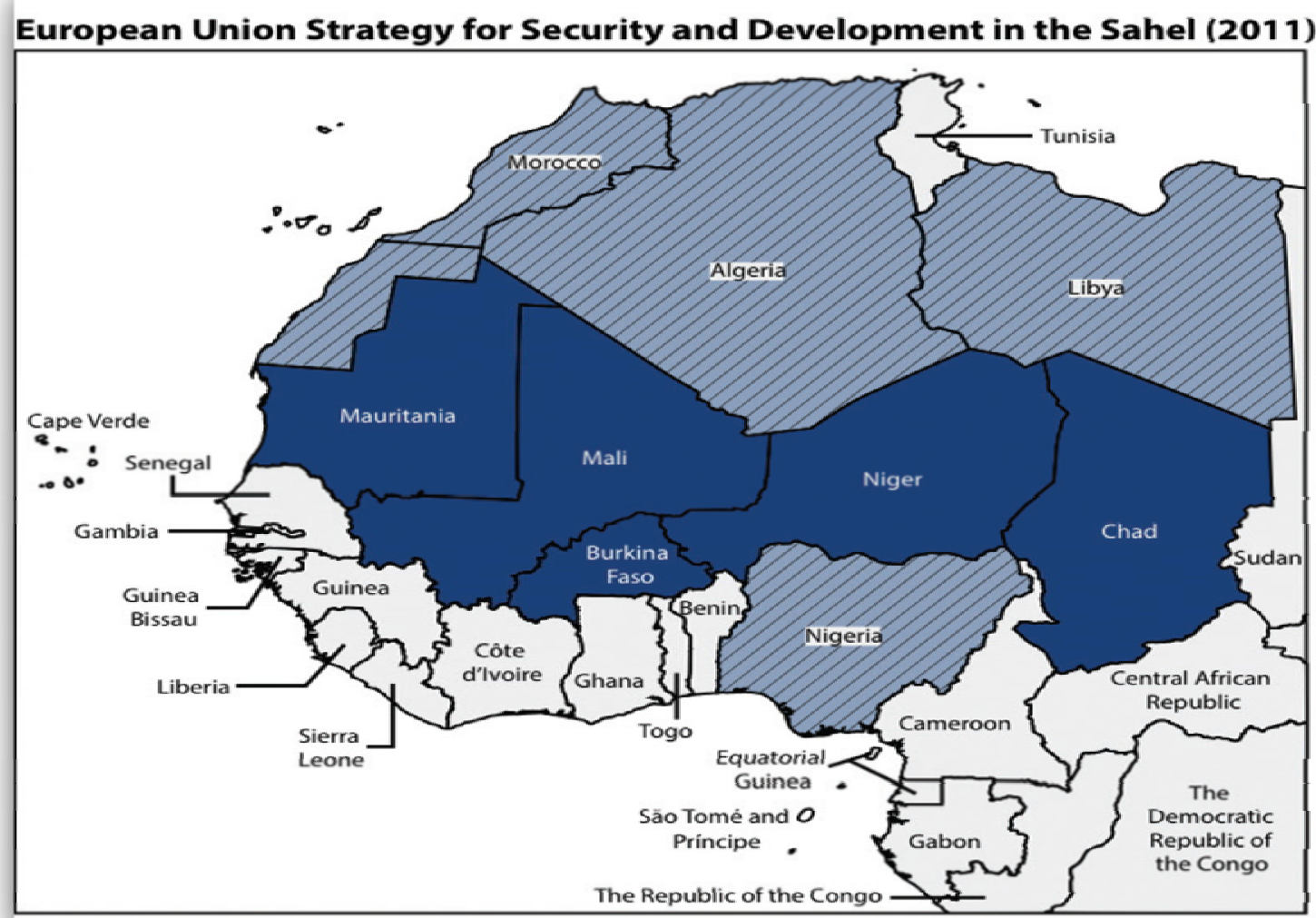

Fuente: Damien Helly, Lori-Anne Théroux-Bénoni, Greta Galeazzi, Ibrahim Maïga and Fatimata Ouédraogo. Sahel strategies: why coordination is imperative. Institute for Security Studies. ISS Policy Brief. N. 76. March 2015, p.3.

Así, y pesar que el Parlamento Europeo tenía un estudio en 2012 sobre la relación terrorismocrimen organizado $^{121}$, no ha sido hasta 2015 que la UE ha lanzado realmente un Plan de Acción de esta estrategia, reafirmando el enfoque seguridad-desarrollo, pero incorporando un contexto que reconoce el problema del crimen organizado transnacional como elemento clave, enfatizando la necesidad de una cooperación EU-Magreb-Sahel para hacer frente a esta situación, que se acerca más a una aproximación comprehensiva: "The security situation of the Sahel region remains extremely volatile, with a particularly precarious situation in northern Mali and around Lake Chad, by means of spill-over effects from the South of Libya and the North of Nigeria. Niger is an important hub and transit country for migratory movements through the Sahel. Challenges linked to the extreme poverty, lack of stability including economic fragility remain as acute as in 2011. Irregular migration and related crimes such as trafficking in human beings and smuggling of migrants, corruption, illicit trafficking and transnational organized crime are thriving particularly where there is weak and/or little presence of any governmental authority. Migration pressure is mounting, with serious implications both for the countries in the region and the EU ${ }^{\prime \prime 22}$. Así, se incluía en el

\footnotetext{
${ }^{121}$ European Parliament. Europe's Crime-Terror Nexus: Links between terrorist and organized crime groups in the European Union. Study. Directorate General for Internal Policies. Policy Deparment. Octubre 2012.

${ }^{122}$ Council conclusions on the Sahel Regional Action Plan 2015-2020. Bruselas, 20 abril 2015.7823/15. Annex. pág. 7.
} 
llamado "strategic focus" como cuarto punto básico "Border management and fight against illicit trafficking and transnational organised crime" ${ }^{123}$, estableciendo también toda una serie de medidas tanto regionales como por países del Sahel para poner en marcha en 2015-16 ${ }^{124}$. Desgraciadamente, la corrupción está haciendo que el crimen y el gobierno en ciertas zonas del Sahel y África occidental están tan interrelacionados que los sistemas judiciales y el imperio de la ley realmente lo que hacen es proteger, facilitar y permitir la impunidad, creando de facto una forma de vida sobre las rutas de tráficos ilícitos ${ }^{125}$. Así, asistimos a un imaginario caos en el área cuando, de hecho, existe un sistema cuando menos mixto en donde hay mecanismos de gobierno híbridos o simbióticos, entre las instituciones del estado, los grupos terroristas, el crimen organizado y la población ${ }^{126}$, creando una "dinámica de hierro" de difícil solución (véase Figura 8).

Figura 9

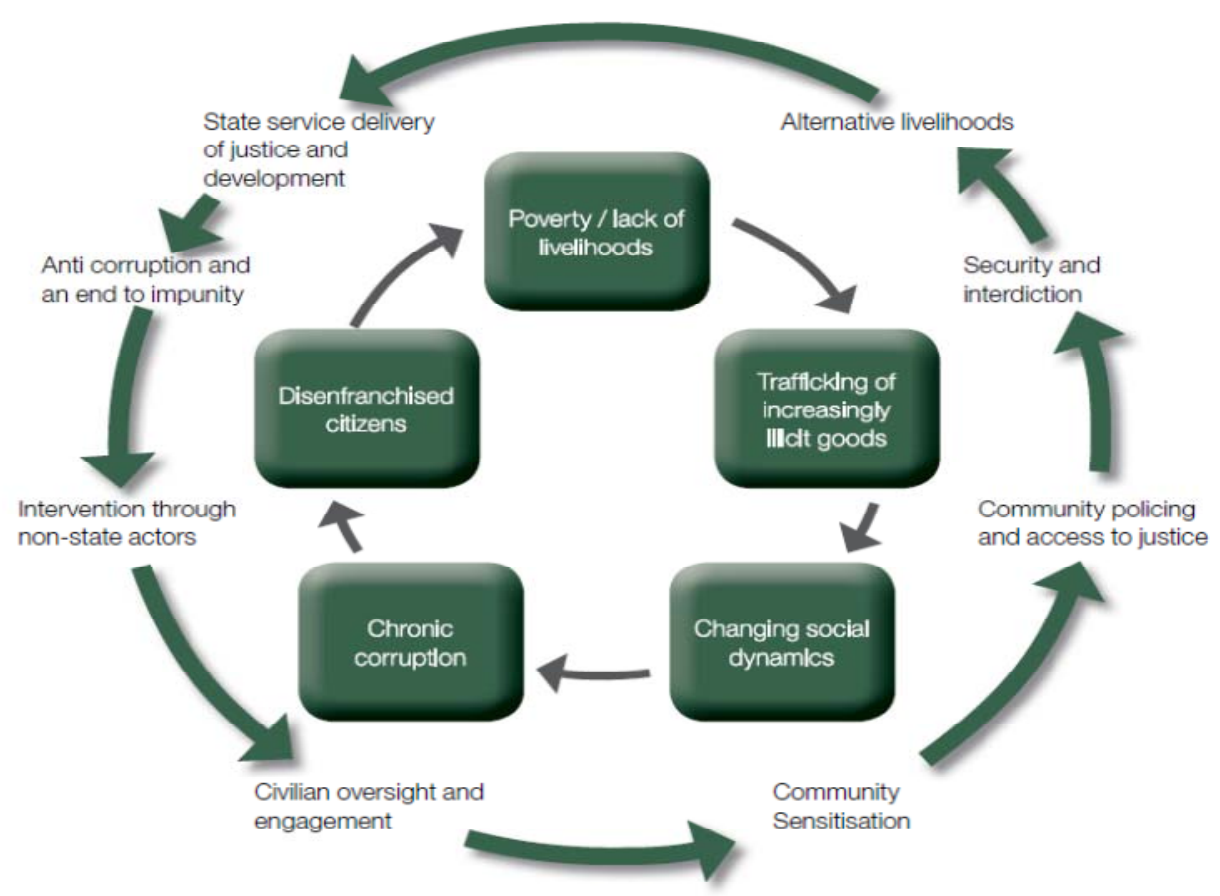

Fuente: Reitano, T. and Shaw, M.: "People's perspectives of organised crime in West Africa and the Sahel". Paper 254. Institute of Security Studies. Pretoria, abril 2014, p.15.

\footnotetext{
${ }^{123}$ Ibid. Pág. 13. In terms of strategic focus it seems particularly important to further develop:

1) Preventing and countering radicalisation;

2) Create appropriate conditions for Youth;

3) Migration and mobility;

4) Border management and fight against illicit trafficking and transnational organized crime.

${ }^{124}$ Addendum, Ibid. Págs. 25-65.

${ }^{125}$ Reitano, Tuesday. and Shaw, Mark. "People's perspectives of organised crime in West Africa and the Sahel". Paper 254. Institute of Security Studies. (Pretoria, Sudáfrica, abril 2014), p.2, en https://www.issafrica.org/uploads/Paper254.pdf

${ }^{126}$ Véase las ya citadas Madsen, F. "Corruption: A Global Common Evil", The RUSI Journal, 158:2. 2013. PP. 26-38; Cockayne, J . "Chasing Shadows", The RUSI Journal, 158:2, 2013. Pp.10-24; Keister, J. "The Illusion of Chaos .Why Ungoverned Spaces Aren't Ungoverned, and Why That Matters". Cato Institute. Policy Analysis. Number 766. (9 de diciembre de 2014).
} 
Si analizamos las medidas adoptadas a nivel regional haciendo una valoración específica por países, es importante subrayar que en el caso de Libia, se han puesto en marcha medidas específicas. Así, España forma parte del grupo reducido P3+ 5 (EE.UU., Reino Unido, Francia, Alemania, Italia, Naciones Unidas, Unión Europea y España) y el grupo de la Unión Africana. En este sentido, la celebración de la conferencia de septiembre de 2014, con la asistencia de 21 ministros y representantes de organizaciones internacionales (ONU, UE, Unión por el Mediterráneo, Unión Africana y Liga Árabe) y el ofrecimiento de acoger una nueva conferencia para apoyar al nuevo gobierno de unidad nacional es una muestra de ello.

En lo que respecta a futuras actuaciones en Libia se buscará principalmente: la continuidad con los proyectos bilaterales en materia de cooperación en seguridad; seguir trabajando en el seno de la UE, particularmente en los aspectos de seguridad y en temas migratorios, en los que España propugna el enfoque integrado que viene aplicando en el llamado Proceso de Rabat; apoyo del programa de asesoramiento de la OTAN en materia de defensa, así como apoyar los esfuerzos de mediación realizados por el Enviado Especial Bernardino León, en coordinación con la comunidad internacional, así como mantener el contacto con actores clave como la Liga Árabe, la Unión Africana y los países vecinos de Libia para aunar esfuerzos y acompañar a las partes a la mesa de negociación.

Por otro lado, el caso de Mali es paradigmático puesto que en el Sahel se debe abordar de un modo conjunto la guerra contra el terrorismo y contra la delincuencia organizada, ante los lazos establecidos entre ambos. Así es importante señalar el importante papel que tradicionalmente juega Francia en este espacio. Ejemplos recientes de ello han sido la intervención militar Serval (2012) en ayuda de Mali y su sustitución en 2014 por la Operación Barkhane con vocación de prevenir y luchar contra el terrorismo y los tráficos ilícitos provenientes de Libia. Si bien la intervención francesa consiguió frenar el avance yihadista hacia el sur de Mali, la inestabilidad continúa a través de ataques asimétricos contra las fuerzas de Naciones Unidas, así como a través de enfrentamientos entre facciones de grupos armados. Todo ello con el telón de fondo de unas negociaciones lanzadas en Argel en julio 2014, marcadas por la desconfianza entre las partes y cuya última fase se iniciará en febrero. Esta intervención vino acompañada de la adopción de la Resolución 2100 del Consejo de Seguridad de NN.UU que estableció la MINUSMA, una misión de mantenimiento de la paz que comenzó a desplegarse a partir del 1 de julio de 2013. Cabe destacar que en el ámbito político, España celebra los esfuerzos de Mali en el marco del Proceso de Argel, puesto que una paz duradera pasa por un diálogo inclusivo y constructivo entre todas las partes. España defiende, que la firma de este acuerdo de paz debe marcar no sólo el fin del conflicto, sino también el inicio de la refundación del país sobre bases sólidas que eviten futuras crisis. Del mismo modo, cabe señalar la gran importancia a la labor de las organizaciones africanas, con especial mención a la Unión Africana y la CEDEAO, que, junto con la labor de la UE y la de otros actores sobre el terreno, contribuyen a la estabilidad y desarrollo de la región. En particular la UE, por su parte, ha puesto en marcha una operación EUTM Mali, para acompañar a las Fuerzas Armadas malienses en su proceso de formación y reestructuración, y cuyo mando es asumido actualmente por España.

Además, se han puesto en marcha otros mecanismos, como la Conferencia Regional sobre Seguridad de Fronteras. En la segunda ${ }^{127}$ se reunieron 19 países y diversas organizaciones internacionales, para reforzar una política de cooperación en este ámbito ${ }^{128}$. El

\footnotetext{
${ }^{127}$ Celebrado en Rabat (Marruecos), el 14 de noviembre de 2013. Congregó a ministros nacionales de Interior y de Asuntos Exteriores de 19 países de la región.

${ }^{128}$ Díez Alcalde, Jesús. "II Conferencia Regional Sobre Seguridad de Fronteras: Por la Estabilidad del Magreb y Sahel". IEEE 64/2013. (27 de noviembre de 2013), en:
} 
objetivo principal de la primera conferencia de Trípoli (liderada por el entonces Consejo Nacional de Transición), era restaurar el control y la seguridad de las fronteras libias, gravemente afectadas por el conflicto interno, el refuerzo de la cooperación regional. Además de mostrar la determinación de los países del Magreb y del Sahel para compartir estabilidad y seguridad, estas dos conferencias ministeriales han corroborado la determinación de la comunidad internacional para colaborar en la resolución de la crisis fronteriza que socava el futuro de esta región africana. En Rabat, la presencia de numerosas organizaciones internacionales y de una amplia representación de los países mediterráneos de Europa, incluida España, ha puesto de manifiesto que el terrorismo yihadista y la criminalidad organizada, en especial el tráfico de armas, drogas y seres humanos, constituyen una preocupante amenaza y un enorme desafío no sólo para África, sino para todos los países que, por su proximidad, sufren sus consecuencias ${ }^{129}$. Otra iniciativa a mencionar es la aprobación por parte de la Unión Europea, a través del Servicio Exterior Europeo, creó una estrategia para la seguridad y el desarrollo en el Sahel en el año $2011^{130}$.

Por materias es importante subrayar las medidas y líneas de acción desarrolladas en la lucha contra las drogas, como la Estrategia sobre Drogas 2013-2020 de la UE y su Plan de Acción de la UE en materia de lucha contra la droga 2013-2016. Por otro lado, en lo que a la lucha contra la trata de seres humanos, se ha incrementado la cooperación a nivel nacional e internacional. Por un lado el CITCO, además del Cuerpo Nacional de Policía y la Guardia Civil, vienen desarrollando diferentes acciones conjuntas en la lucha contra la trata tanto a nivel nacional como internacional, estando presentes en la Plataforma Multidisciplinar Europea contra las Amenazas Criminales (EMPACT) de la Unión Europea, instrumento éste que se enmarca como uno de los elementos básicos del Ciclo Político de la UE 2014/2017 (EU Policy Cicle). En dicha plataforma se han definido una serie de prioridades estratégicas en la Unión Europea para luchar contra el Crimen Organizado y los Delitos Graves, siendo una de ellas la trata de seres humanos. El Director del CITCO ha sido designado Coordinador Nacional EMPACT, con fecha 8 de abril de 2014, a los efectos de lo dispuesto en la Instrucción de la Secretaría de Estado de Seguridad no 4/2014, de fecha 7 abril, por la que se crea la figura de Coordinador Nacional Empact. Asimismo, España participa en el EMPACT de TSH. El CITCO y las Fuerzas y Cuerpos de Seguridad del Estado en representación de España ha participado en los 17 Planes de Acción Operativa que desarrollaba esta Prioridad y además junto con Bélgica han presentado en Europol, el día 31 de octubre de 2014, los dos informes de los Planes de Acción Operativos. Por otro lado, destaca la Transposición completa de la Directiva 2011/36/UE relativa a la prevención y lucha contra la trata de seres humanos y la protección de las víctimas.

En este sentido, el 16 de abril de 2014 España organizó en Alicante una reunión de Ministros de Asuntos Exteriores del Grupo Mediterráneo (España, Francia, Portugal, Italia, Malta, Grecia y Chipre) en la que se aprobó una Declaración sobre las Acciones a desarrollar en materia migratoria. Por otra parte, en la Unión Europea se ha creado una Task Force para el Mediterráneo con la misión de impulsar acciones para evitar la inmigración ilegal.

Todas y cada una de estas medidas deben ir encaminadas a desarrollar una respuesta coherente y coordinada. Se debe superar de una vez por todas las acciones enfocadas en términos nacionales, puesto que el crimen organizado trasnacional no se supedita a acciones nacionales. Las acciones más efectivas son aquéllas que tienen un enfoque regional y

\footnotetext{
http://www.ieee.es/Galerias/fichero/docs analisis/2013/DIEEEA64-

2013 ConferenciaSeguridadFronteras.JDA.pdf

${ }^{129}$ Ibid.

130 European Union External Action Service. Strategy for Security and Development in the Sahel. http://eeas.europa.eu/africa/docs/sahel strategy en.pdf
} 
subregional, y que tienen también en cuenta todos elementos de la ecuación: los mercados de origen y los de destino, así como los flujos y la demanda de los tráficos ilícitos ${ }^{131}$.

Los programas a nivel regional han obviado la repercusión de las capacidades de construcción de iniciativas propias en el seno de la región del Sahel y del Magreb, así como el nivel y el reparto de liderazgo entre los países de la región, por lo que no han contemplando las posibles rivalidades en este sentido entre Marruecos y Argelia para liderar programas autóctonos en la región, así como los propios intereses de los países de la región. A este respecto, tanto el Arab Maghreb Union (AMU) como el Community of Sahel-Saharan States (CEN-SAD) se encuentran en parálisis, debido principalmente a estas rivalidades internas ${ }^{132}$.

\subsection{Mecanismos de lucha promovidas por España}

En el año 2014 el Gobierno español unificó los dos servicios que se dedicaban a coordinar la lucha contra el terrorismo y el crimen organizado, fusionando por un lado, el Central Nacional de Coordinación Antiterrorista (CNCA) y, por otro, el Centro el Centro de Inteligencia Contra el Crimen Organizado (CICO), creando en su lugar el Centro de Inteligencia contra el Terrorismo y el Crimen Organizado (CITCO) $)^{133}$.

A pesar de que este centro no tiene información sobre la región tratada, es importante subrayar cómo se ha realizado una simbiosis identificando como una amenaza conjunta, esto es, híbrida, por lo que también ha unificado la lucha contra dicha amenaza: crimen organizado y terrorismo.

Dentro de los proyectos EMPACT de la Unión Europea, España lidera de forma prioritaria la lucha contra cocaína, que supone una amenaza en Europa. España asimismo lidera: Plataforma Bogotá: Incremento del intercambio de información sobre tráfico de drogas, en especial cocaína, en la Región Andina, en esta plataforma liderada por España; y SEISOCO: Impulso al intercambio de información estratégica sobre crimen organizado, fundamentalmente sobre tráfico de drogas, en Latinoamérica liderado por España a través del CITCO, si bien ninguna está enfocada específicamente a la región del Magreb.

A la hora de analizar la criminalidad organizada proveniente del norte de áfrica, y que afecta e incide directamente en la seguridad del país, es importante subrayar que el tráfico de drogas, es una de las siete prioridades operativas en la Estrategia Española contra el Crimen Organizado $^{134}$. De este modo, nuestro país, sigue siendo, principalmente por su posición geográfica y estratégica un importante punto de acceso de entre Europa y el continente

\footnotetext{
131 The Nineteenth Annual International Peace Institute New York Seminar: Organized crime and conflict in the Sahel-Maghreb: understanding the linkages, responding to the threat. Nueva York, 8 de abril de 2014.

${ }^{132}$ Lacher, Wolfram: "Organized crime and terrorism in the Sahel". SWP Comments, enero de 2011, en http://www.swp-berlin.org/fileadmin/contents/products/comments/2011C01 lac ks.pdf

${ }^{133}$ Real Decreto 873/2014, de 10 de octubre, por el que se modifica el Real Decreto 400/2012, de 17 de febrero, por el que se desarrolla la estructura orgánica básica del Ministerio del Interior.

${ }^{134}$ Como ejemplo de la efectividad de los mecanismos puestos en marcha a nivel nacional, entre las operaciones más relevantes, vinculadas a la criminalidad organizada, se pueden destacar las siguientes: Operación Relámpago, llevada a cabo por la Guardia Civil, el Cuerpo Nacional de Policía y la Policía Polaca en la provincia de Almería, siendo detenidas un total de 6 personas: marroquíes (3), polacas (2) y española (1); Operación Kebab llevada a cabo por el Cuerpo Nacional de Policía en la provincia de Almería, siendo detenidas un total de 10 personas: rumanas (7) y españolas (3). Las víctimas eran captadas en Rumania mediante el procedimiento conocido como "love story" (seducción y posterior engaño); Operación Traslado, llevada a cabo por el Cuerpo Nacional de Policía en la provincia de Palma de Mallorca, siendo detenidas un total de 15 personas: búlgaras (11), rumanas (2), españolas (1) y suizas (1). Las víctimas eran captadas en Bulgaria mediante engaño sobre la actividad real que iban a desarrollar.
} 
africano $^{135}$. En lo que a la droga se refiere, y tal y como hemos señalado en el apartado de las rutas del crimen, las rutas marítimas siguen siendo las más utilizadas para la introducción del cannabis desde el norte de África. Del mismo modo, y tal y como hemos señalado, estas rutas se han ido desplazando hacia el este y el oeste conforme se desplegaba el Sistema Integral de Vigilancia Exterior (SIVE) en el sur de España.

Destacar que se mantiene una relación de cooperación policial muy estrecha, sin precedentes, con el Reino de Marruecos, que es decisiva para combatir el terrorismo yihadista. La prueba de ello es que se han realizado operaciones policiales conjuntas (que son mucho más que operaciones con información compartida, pues implica la coordinación y participación conjunta de fuerzas policiales de España y Marruecos en todas las fases del operativo).

Asimismo es importante destacar el papel que España ha desempeñado, implicándose con varias medidas que van desde, la contribución a las misiones de la UE en la zona, el apoyo militar a las operaciones francesas, o los programas de control de fronteras. En particular en materia de inmigración por otro lado, cabe destacar en julio de 2014 la creación del Comité Especializado de Inmigración. Se están tramitando en este campo el Plan de Contingencia Global frente a Crisis Migratorias, el Protocolo de Coordinación de Salvamento Marítimo, la Revisión normativa de las propuestas de reforma en curso y el Informe de Riesgos del Fenómeno Migratorio en el Mediterráneo. Esto ha sido superado por la actual crisis migratoria sufrida en Europa, que ha modificado la ruta de entrada, de España hacia Grecia e Italia ${ }^{136}$. En términos relativos hemos tenido un aumento del $15 \%$ de llegadas en 2014, que contrasta con el 277\% del Mediterráneo Central, el 104\% del Oriental y el $87 \%$ de los Balcanes. Cabe destacar igualmente, que España participa en las Asociaciones de movilidad con Marruecos, Túnez y Jordania, principal instrumento de la UE en sus relaciones con terceros países en materia migratoria. España es un socio activo en el Proceso de Rabat, centrado en los aspectos migratorios del Norte de África y África Occidental, España también se ha incorporado al Proceso de Jartum, relativo a la ruta migratoria del Cuerno de África. Por último, hay que señalar que España recibirá 452 millones de euros procedentes de fondos comunitarios en materia de inmigración en el periodo 2014-2020. (257 millones de euros con cargo al Fondo de Asilo y Migración otros 195 millones de euros con cargo al instrumento de apoyo a las fronteras exteriores y los visados $)^{137}$.

\section{Conclusiones}

En la Unión Europea no existe realmente una política unificada Magreb-Sahel y en términos de crimen organizado y terrorismo, el Sahel no se puede separar del Magreb, (véase Argelia y Libia sobre todo-aunque no únicamente- en relación a Mali, Níger y Chad). Y, como hemos visto, hay una comprensión limitada y parcial del problema en términos de amenaza como en soluciones viables, por lo que el flanco sur se configura hoy como un espacio fundamental en lo que a amenazas para la seguridad se refiere. Sin embargo esta área se ha ampliado

\footnotetext{
${ }^{135}$ Barras, Raquel: "Crimen organizado transnacional: mecanismos de lucha en la nueva Estrategia de Seguridad Nacional" en Marquina, Antonio (2015): La Estrategia de Seguridad Nacional 2013. Un Pavimento Deslizante. Madrid, UNISCI, pp. 447-486.

${ }^{136}$ Sin ánimo de reducir la magnitud del problema, la situación en España es diferente a la de otros países. A nuestro país llegaron 7.500 personas irregularmente por el Mediterráneo, Ceuta, Melilla y Canarias, frente a 170.800 que llegaron por el Mediterráneo Central, 50.500 por el Oriental y 37.000 por la ruta de los Balcanes. (Datos del año 2014).

137 "La Comisión Europea aprueba 2.400 millones de euros para apoyar a países en crisis migratoria" El Mundo, 3 de agosto de 2015, en http://www.elmundo.es/internacional/2015/08/10/55c89cdaca4741ec208b4577.html
} 
irremediablemente a Chad, Burkina Faso y Nigeria, sobre todo por la acción de Boko Haram, desbordando la visión, proyección y estrategia de la UE.

Aunque la estrategia establece bastante correctamente el contexto, los objetivos y medidas no ataca el problema de fondo, ni aborda otras causas profundas como la financiación por algunos estados del Golfo de movimientos religiosos radicales que se ha demostrado contribuyen a la expansión del terrorismo y, además, no se establece ningún planteamiento o medidas relativas a la expansión de Boko Haram y sus posibles consecuencias. A pesar de que el Sahel Regional Action Plan 2015-2020 incluye Burkina Faso, Mauritania y Chad, las medidas tomadas son reducidas, muy recientes y probablemente insuficientes y tardías desde el punto de vista de la dinámica y sinergia entre terrorismocrimen organizado en un contexto de corrupción. La UE sigue manteniendo un enfoque seguridad-desarrollo, básicamente en una concepción de seguridad humana ${ }^{138}$, a pesar de que este enfoque es altamente discutible para enfrentarse a este tipo de amenazas. Los cárteles del crimen organizado en la mayoría de los casos consiguen más poder cuando cooperan con terroristas. Al terrorismo internacional sólo se le puede ganar con eficacia si las estrategias de lucha contra el terrorismo de los estados tienen en cuenta esta simbiosis cada vez mayor. Para abordar este nexo de forma más eficaz, las instituciones dedicadas a la lucha contra el terrorismo y la delincuencia organizada deben de cooperar más estrechamente, con todos los condicionantes que esto supone al tratarse en múltiples ocasiones de coaliciones ad hoc con estructuras, culturas y mentalidades diferentes, sin pretender imponer condicionalidades, que se han mostrado inservibles, y desarrollar nuevas respuestas múltiples para satisfacer estas nuevas amenazas a nivel nacional, regional y mundial. Probablemente la creación o fusión de organizaciones bajo mecanismos de agencia, mucho más flexibles y preparados, con aproximaciones comprehensivas e integradas, con todas las dificultades que esto conlleva, es probablemente la solución.

En este sentido "la amenaza en la región del Sahel no sólo es el terrorismo islamista, sino también el crimen organizado y el tráfico de ilícitos, de forma especial el tráfico de drogas, donde la implicación de las estructuras terroristas dificultan una lucha eficaz de los países del Magreb, de Europa y Estados Unidos [...] La combinación de los actos criminales con el negocio de la droga han transformado, en el norte de Mali, el proyecto yihadista de AQMI. El uso del discurso nacionalista-religioso sigue siendo la base de este grupo terrorista y de sus aliados para conseguir nuevos adeptos a la causa que ya no es sólo político-religiosa sino que se fundamenta en la creación de una economía criminal"139.

\footnotetext{
${ }^{138}$ Este concepto que suena bien y hacer quedar bien, se ha utilizado incluso a nivel oficial por militares y civiles de forma inadecuada, sin definir su contenido -hay más de cuarenta definiciones que lo hacen no operativo- y confunde en múltiples ocasiones la seguridad con el bienestar y la dignidad, cuestiones distintas de la seguridad (supervivencia).

${ }^{139}$ Mesa, Beatriz. "La transformación del Yihadismo en el norte de Mali: de causa política a economía criminal". UNISCI Discussion Papers, No 34 (Enero / January 2014), en http://revistas.ucm.es/index.php/UNIS/article/viewFile/44835/42245
} 